NIPER-509

Distribution Category UC-125

\title{
THE THERMODYNAMIC PROPERTIES OF 2,3-BENZOTHIOPHENE
}

Topical Report
By
NIPER- -509
R. D. Chirico
DE9 1 002218

S. E. Knipmeyer
A. Nguyen
W. V. Steele

January 1991

Work Performed Under Cooperative Agreement No. DE-FC22-83FE60149

\author{
Prepared for \\ U.S. Department of Energy \\ Assistant Secretary for Fossil Energy
}

W. D. Peters, Project Manager

Bartlesville Project Office

P.O. Box 1398

Bartlesville, OK 74005

Prepared by

IIT Research Institute

National Institute for Petroleum and Energy Research

P.O. Box 2128

Bartlesville, OK 74005 


\section{EXECUTIVE SUMMARY}

Upgrading of heavy fossil fuels is normally done by hydrotreating in the presence of catalysts, such as sulfided $\mathrm{CoO}-\mathrm{MOO}_{3} / \gamma-\mathrm{Al}_{2} \mathrm{O}_{3}$, at 5 to $15 \mathrm{MPa}$ pressure of hydrugen and 575 to $700 \mathrm{~K}$. The efficient use of expensive hydrogen in this process is essential to the economic viability of alternative fuel sources (heavy petroleum, tar sands, shale oil, and the products of the liquefaction of coal).

2,3-Benzothiophene is widely used as a model compound in catalyst-comparison and kinetics studies of the hydrodesulfurization (HDS) mechanism. To perform a thermodynamic analysis of the 2,3-benzothiophene/hydrogen reaction network at the process temperatures, Gibbs energies of reaction at those high temperatures are required for the molecules involved. At present, the thermodynamic information necessary for the analysis of possible reaction pathways and stable intermediates is not available. Only crude estimates based on the thermodynamic properties of thiophene are available. The studies reported here begin to provide the required information.

A second application of the results reported ilere is in the area of property estimations. Because of the enormous number of individual compounds present in fossil materials, group-contribution and corresponding-states methods are employed to estimate thermodynamic properties in the absence of measured values. Much of the empirical information necessary to exiend existing group-contribution parameterizations to include polycyclic aromatic sulfur-containing species does not exist. The studies reported here provide the basis for the accurate estimation of many physical properties for this class of molecules over a broad temptiature range. 


\begin{abstract}
Measurements leading to the calculation of the ideal-gas thermodynamic properties for 2,3-benzothiophene are reported. Experimental methods included adiabatic heatcapacity calorimetry, comparative ebulliometry, inclined-piston gauge manometry, and differential-scanning calorimetry (d.s.c.). The critical temperature and critical density were determined with the d.s.c., and the critical pressure was derived. Entropies, enthalpies, and Gibbs energies of formation were derived for the ideal gas for selected temperatures between $260 \mathrm{~K}$ and $750 \mathrm{~K}$. These values were derived by combining the reported measurements with values published previously for the enthalpy of combustion, the enthalpy of fusion, and the absolute entropy and enthalpy of the liquid at the triple-point temperature. Measured and derived quantities were compared with available literature values.
\end{abstract}

\title{
ACKNOWLEDGEMENTS
}

The authors acknowledge the financial support of the Office of Fossil Energy of the U.S. Department of Energy. This research was funded within the Advanced Research Section of the Coal Liquefaction program as part of the Cooperative Agreement DE-FC22. 83 FE60149.

The authors gratefully acknowledge Professor E. J. "Pete" Eisenbraun and his research group at Oklahoma State University for purification of the samples, and the assistance of I. A. Hossenlopp in vapor-transfer of the materials prior to the calorimetric measurements. 


\section{TABLE OF CONTENTS}

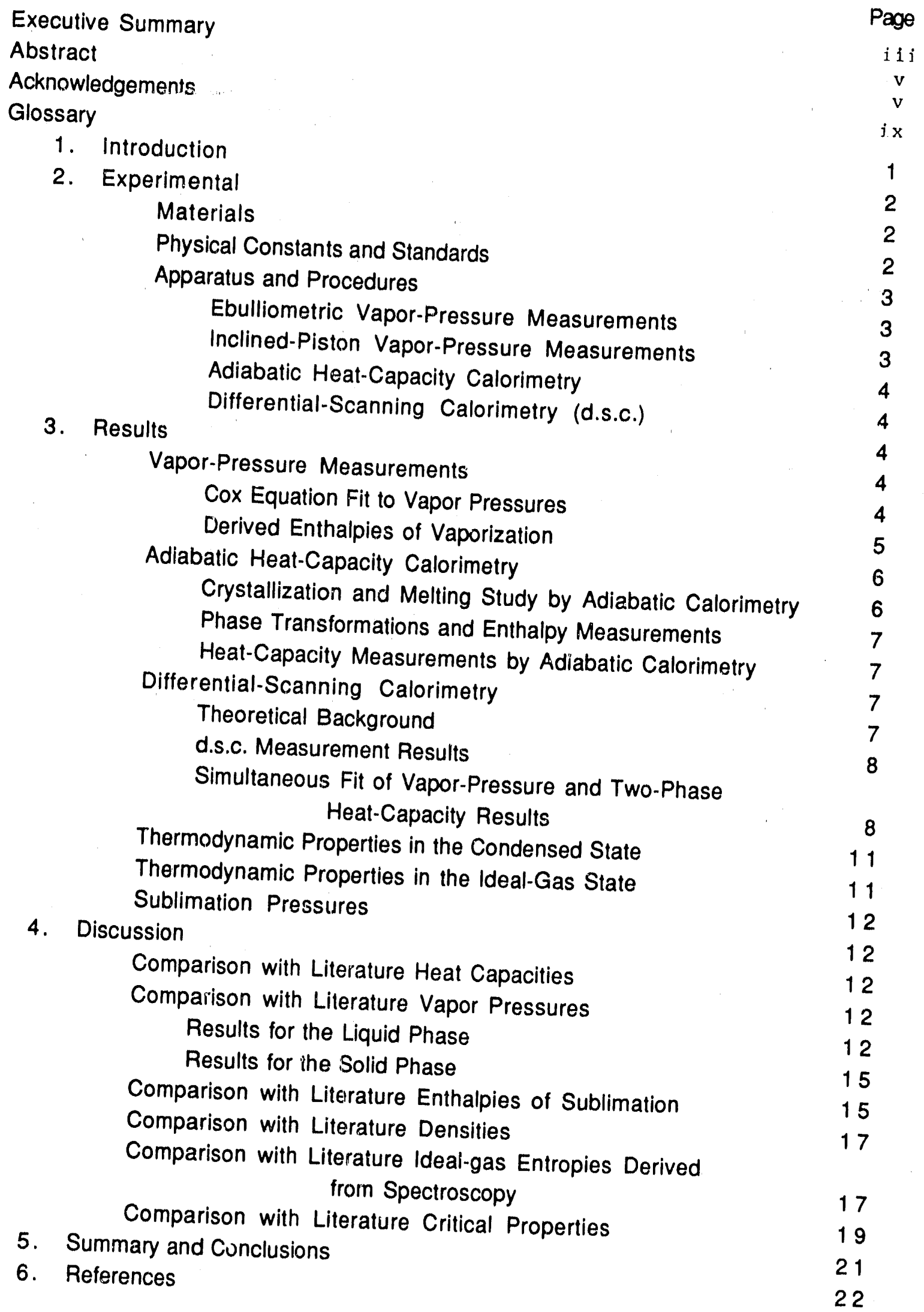




\section{LIST OF TABLES}

TABLE 1. Calorimeter and sample characteristics 24

TABLE 2. Summary of vapor-pressure results 25

$\begin{array}{lll}\text { TABLE } & 3 . \text { Cox equation coefficients } & 27\end{array}$

TABLE 4. Enthalpies of vaporization and entropies of compression obtained from $\begin{array}{ll}\text { the Cox and Clapeyron equations } & 28\end{array}$

TABLE 5. Experimental molar enthalpy measurements 29

TABLE 6. Experimental molar heat capacities at vapor-saturation pressure determined by adiabatic calorimetry 30

TABLE 7. Experimental $C_{x, m}^{\prime \prime} / R$ values 31

TABLE 8. Densities and temperatures for the conversion from two phases to a single phase for 2,3-benzothiophene 32

TABLE 9. Parameters for equations (11) and (12) and critical constants 33

TABLE 10. Values of $C_{v, m}^{\prime l}\left(\rho=\rho_{\text {sat }}\right) / R$ and $C_{\text {sat }, m} / R$

TABLE 11. Molar thermodynamic functions at vapor-saturation pressure 35

TABLE 12. Thermodynamic properties in the ideal-gas state 36

TABLE 13. Comparison of experimental and estimated critical properties $\quad 37$

\section{LIST OF FIGURES}

Page

FIGURE 1. Vapor-liquid coexistence region for 2,3-benzothiophene 9

FIGURE 2. Deviation plot for 2,3-benzothiophene heat capacities 13

FIGURE 3. Deviation plot for literature vapor pressures 14

FIGURE 4. Deviation plot for sublimation pressures 16

FIGURE 5. Deviation plot for 2,3-benzothiophene densities 18

FIGURE 6. Deviation plot for ideal-gas entropy values 20 


\section{GLOSSAFYY}

This report is written with close adherence to the style adopted by The Journal of Chemical Thermodynamics. A complete description of the style can be found in the January 1990 issue of the Journal of Chemical Thermodynamics. This glossary summarizes the main points with respect to the symbol usage.

Throughout this report only $S I$ units are used in reporting thermodynamic values. All values are given in dimensionless units i.e., physical quantity $=$ number $X$ unit; for example $\rho /\left(\mathrm{kg} \cdot \mathrm{m}^{-3}\right)$ rather than " $\rho\left(\mathrm{kg} / \mathrm{m}^{3}\right)$ " or " $\rho \mathrm{kg} / \mathrm{m}^{3}$ ". Molar values, i.e., intensive functions, are denoted by the subscript " $m$ ", e.g., $C_{s a t} m$, whereas extensive functions do not have the subscript. In addition, since thermodynamic values are pressure dependent, they are reported in terms of a standard pressure $\mathrm{p}^{\circ}$, which in this report is $101.325 \mathrm{kPa}$ (one atmosphere).

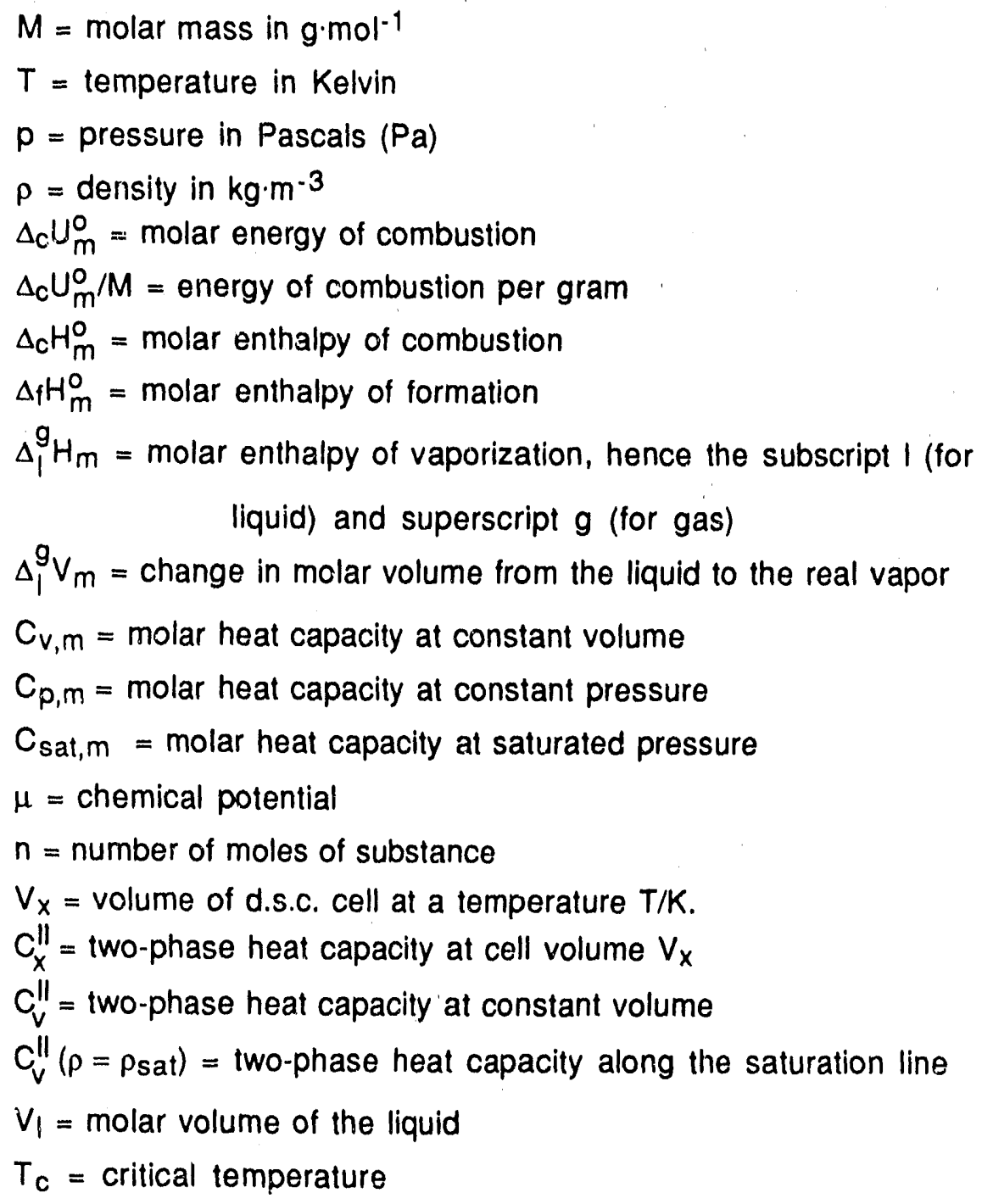




$$
\begin{aligned}
& p_{c}=\text { critical pressure } \\
& \rho_{c}=\text { critical density } \\
& T_{r}=\text { reduced temperature }=T / T_{c} \\
& p_{r}=\text { reduced pressure }=p / \rho_{c} \\
& \rho_{r}=\text { reduced density }=\rho / \rho_{c} \\
& l g=\log _{10} \\
& \omega=\text { acentric factor }=\left[-l g\left(p_{x} / p_{c}\right)-1\right] ; p_{x} \text { is the vapor pressure at } T_{r}=0.7 \\
& \Delta_{0}^{T} S_{m}^{\circ}=\text { molar entropy at temperature } T / K \text { (relative to the entropy at } T=0 \mathrm{~K} \text { ) } \\
& \Delta_{0}^{T} H_{m}^{0}=\text { molar enthalpy at temperature } T / K \text { (relative to the crystals at } 0 \mathrm{~K} \text { ) } \\
& \Delta_{c o m p} S_{m}=\text { molar entropy of compression of a gas } \\
& \Delta_{i m p} S_{m}=\text { gas imperfection term } \\
& T \rightarrow 0=\text { Zero Kelvin }
\end{aligned}
$$

To avoid listing units in tables, entropies are reported as divided by the gas constant $R$, and enthalpies and Gibbs energies are generally reporied divided by the product of the gas constant and temperature, R.T. Units of time are $s$ (seconds) or h (hours). 


\section{Introduction}

This research was completed as part of a program, funded by the $U$. S. Department of Energy (DOE) Office of Fossil Energy, Advanced Research Section of Coal Liquefaction (ARL) research program, in which thermochemical and thermophysical properties are determined for "key" organic compounds present in alternative crudes (i.e., shale oil, tar sands, heavy petroleum, and particularly liquids derived from coal). Important reactions involved in the upgrading of these alternative fuel sources include hydrogenation of aromatics, hydrodesulfurization (HDS), hydrodenitrogenation (HDN), and hydrodeoxygenation (HDO). The efficient use of expensive hydrogen in these processes is essential to their economic viability.

Upgrading of heavy fossil fuels is done normally by hydrotreating in the presence of catalysts, such as sulfided $\mathrm{CoO}-\mathrm{MoO}_{3} / \gamma-\mathrm{Al}_{2} \mathrm{O}_{3}$, at 5 to $15 \mathrm{MPa}$ pressure of hydrogen and 575 to $700 \mathrm{~K}$.(1) 2,3-Benzothiophene is widely used as a model compound in catalyst-comparison studies and kinetics studies of the HDS mechanism.(2) To perform a thermodynamic analysis of the 2,3-benzothiophene/hydrogen reaction network at the process temperatures, Gibbs energies of reaction at those high temperatures are required for the molecules involved. At present, the thermodynamic information necessary for the analysis of possible reaction pathways and stable intermediates is not available.

A second application of the results reported here is in the area of property estimations. The enormous number of individual compounds present in fossil materials makes it necessary to use group-contribution and corresponding-states methods to estimate thermodynamic properties in the absence of measured values. Much of the empirical information necessary to extend the existing group-contribution parameterization $(3,4)$ to include polycyclic aromatic sulfur-containing species does not exist. The studies reported here begin to provide this information.

High-precision measurements of the heat capacity $(12 \text { to } 330 \mathrm{~K})^{(5)}$ and the energy of combustion(6) for 2,3-benzothiophene were completed in these laboratories many years ago. Vapor pressures, necessary for the calculation of gas-phase Gibbs energies of formation, have been reported in the literature, (7-9) but are inconsistent. The present studies provide the additional information necessary to derive Gibbs energies of forriation for 2,3-benzothiophene from $260 \mathrm{~K}$ to near its critical temperature $(764 \mathrm{~K})$.

Vapor pressures were measured by comparative ebulliometry and irclinedpiston gauge manometry. Heat capacities for the liquid phase were measured by adiabatic 
heat-capacity calorimetry and differential-scanning calorimetry (d.s.c.). A check of the published enthalpy of fusion result $(5)$ was made. The critical temperature and critical density were determined by d.s.c. A value for the critical pressure and Gibbs energies of formation for the ideal-gas were derived. All heat capacities, vapor pressures, and critical properties measured or derived in this research are compared with literature values. Ideal-gas entropies are compared with values derived from spectroscopic analyses reported in the literature.

\section{Exper|mental}

MATERIALS

A commercial sample of 2,3-benzothiophene was purified as follows. The impure sample was treated with picric acid in methanol at $334 \mathrm{~K}$ (molecular proportions 0.7 to 1.1 to 100 for 2,3-benzothiophene, picric acid, and methanol, respectively). The rerulting picrate was recrystallized from methanol. The picrate was cleaved by reaction with basic alumina in a Soxhlet apparatus under argon with ethyl ether as solvent. The liberated 2,3-benzothiophene was concentrated, and final purification was achieved by double distillation at $343 \mathrm{~K}$ and $0.5 \mathrm{kPa}$.

The mole fraction impurities were estimated to be 0.0005 by g.l.c. The high purity of the calorimetric sample was confirmed both in a fractional-melting study completed as part of the adiabatic heat-capacity studies and by the small differences observed between the boiling and condensation temperatures in the ebulliometric vaporpressure measurements. The mole-fraction of impurities determined in the fractionalmelting studies was 0.0008 .

The water used as a reference material in the ebulliometric vapor-pressure measurements was deionized and distilled from potassium permanganate. The decane used as a reference material for the ebulliometric measurements was purified by urea complexation, two recrystallizations of the complex, its decomposition with water, extraction with ether, drying with $\mathrm{MgSO}_{4}$, and distillation at $337 \mathrm{~K}$ and $1 \mathrm{kPa}$ pressure.

\section{PHYSICAL CONSTANTS AND STANDARDS}

Molar values are reported in terms of $M=134.196 \mathrm{~g} \cdot \mathrm{mol}^{-1}$ for 2,3-berizothiophene based on the relative atomic masses of $1981(10) t$ and the gas constant, $R=8.31451 \mathrm{~J} \cdot \mathrm{K}^{-1} \cdot \mathrm{mol}^{-1}$, adopted by CODATA.(11) The platinum resistance thermometers used in these measurements were calibrated by comparison with standard

t The 1981 relative atomic masses were used because the CODATA Recommended Key Values for Thermodynamics (reference 37 ) are based on them. 
thermometers whose constants were determined at the National Institute of Standards and Technology (NIST), formerly the National Bureau of Standards (NBS). All temperatures reported are in terms of the IPTS-68.(12) Measurements of mass, time, electrical resistance, and potential difference were made in terms of standards traceable to calibrations at NIST.

\section{APPARATUS AND PROCEDURES}

Ebulliometric Vapor-Pressure Measurements. The essential features of the ebulliometric equipment and procedures are described in the literature.(13,14). The ebulliometers were used to reflux the substance under study with a standard of known vapor pressure under a common helium atmosphere. The boiling and condensation temperatures of the two substances were determined, and the vapor pressure was derived using the condensation temperature of the standard.(15)

The precision in the temperature measurements for the ebulliometric vaporpressure studies was $0.001 \mathrm{~K}$. Uncertainties in the pressures are adequately described by:

$$
\sigma(p)=(0.001 K)\left\{\left(d p_{r} \theta_{f} / d T\right)^{2}+\left(d p_{x} / d T\right)^{2}\right\}^{1 / 2}
$$

where pref is the vapor pressure of the reference substance and $p_{x}$ is the vapor pressure of the sample under study. Values of $d p_{r e f} / d T$ for the reference substances were calculated from fits of the Antoine equation $(16)$ to vapor piessures of the reference materials (decane and water) reported in reference 15.

Inclined-Piston Vapor-Pressure Measurements. The equipment for these measurel... nts has been described by Douslin and McCullough,(17) and Douslin and Osborn.(18) Recent revisions to the equipment and procedures have been reported.(19) The low pressure range of the inclined-piston measurements, 10 to $3500 \mathrm{~Pa}$, necessitated diligent outgassiris of the sample prior to introduction into the apparatus. Also, prior to the sample introduction, all parts of the cell in contact with the sample were baked at $623 \mathrm{~K}$ under high vaclium $\left(<10^{-4} \mathrm{~Pa}\right.$ ). The thoroughly outgassed samples were pliced in the apparatus, and additional outgassing was performed prior to commencing measurements. Finally, prior to each measurement, a small amount of sample was pumped off. Measurements were made as a function of time to extrapolate the pressure to the time when the pumping valve was closed; i.e., to the time when insignificant amounts of lighi gas had leaked into the system or diffused out of the sample. 
Uncertainties in the pressures determined with the inclined-piston apparatus, on the basis of estimated precision of measuring the mass, area, and angle of inclination of the piston, are adequately described by the expression:

$$
\sigma(p)=1.5 \times 10^{-4} p+0.2 P a .
$$

The uncertainties in the temperatures are $0.001 \mathrm{~K}$.

Adiabatic Heat-Capacity Calorimetry. Adiabatic heat-capacity and enthalpy measurements were made with a calorimetric system described previously. $(19-22)$ The calorimeter characteristics and sealing conditions are given in table 1.1 Energy measurement procedures were the same as those described for studies on quinoline.(19) Thermometer resistances were measured with self-balancing a.c. resistance bridges ( $H$. Tinsley \& Co. Ltd.; Models 5840C and 5840D). Energies were measured to a precision of 0.01 per cent, and temperatures were measured to a precision of $0.0001 \mathrm{~K}$. The onergy increments to the filled calorimeter were corrected for enthalpy changes in the empty calorimeter, for the helium exchange gas, and for vaporization of the sample. The correction to the measured energy for the helium exchange gas was negligible at all temperatures $(<0.001$ per cent). The sizes of the other two corrections are indicated in table 1.

Differential-Scanning Calorimetry (d.s.c.). Differential-scanning calorimetric measurements were made with a Perkin-Elmer DSC-2. Experimental methods were described previously. $(23,24)$

\section{Results}

\section{VAPOR-PRESSURE MEASUREMENTS}

Vapor pressures for 2,3-benzothiophene are reported in table 2. Following previous practice, $(14)$ the results obtained in the ebulliometric measurements were adjusted to common pressures. The common pressures, the condensation temperatures, and the difference between condensation and boiling temperatures for the sample are reported. The small differences between the boiling and condensation temperatures indicated correct operation of the equipment and the high purity of the sample.

Cox Equation Fits to Vapor Pressures. Previous studies by Scott and Osborn(25) showed that the Cox equation(26) can represent measured vapor pressures adequately from the

\footnotetext{
I All tables are given at the end of this report.
} 
triple-point pressure to $0.3 \mathrm{MPa}$. Scott and Osborn also showed that the Antoine equation, the most commonly used to represent vapor pressures, does not extrapolate well outside the experimental range. In contrast, the Cox equation extrapolates with reasonable precision over a $50 \mathrm{~K}$ range. (25)

The Cox equation in the form:

$$
\ln \left(p / p_{\text {ref }}\right)=\left\{1-\left(T_{r e f} / T\right)\right\} \exp \left\{A+B(T / K)+C(T / K)^{2}\right\},
$$

was fitted to the experimental vapor pressures with Pref and Tref chosen to be the critical pressure and critical temperature, respectively. The critical temperature was determined from measurements with a d.s.c., and the critical pressure was calculated by a fitting procedure. Both are described later in this report. In the present Cox equation fits, the sums of the weighted squares in the function:

$$
\Delta=\ln \left\{\ln \left(\mathrm{p} / \mathrm{p}_{\mathrm{ref}}\right) /\left(1-T_{\mathrm{ref}} / \mathrm{T}\right)\right\}-A-B(T / K)-C(T / K)^{2},
$$

were minimized. Tref and pref were not allowed to vary in the fit. The weighting factors $W$, the reciprocals of the variance in $\Delta$ derived from the propagation of errors in the temperature and pressure determinations, are defined by:

$$
W=\left\{(\partial \Delta / \partial T)_{p}^{2} \sigma(T)^{2}+(\partial \Delta / \partial p)_{T}^{2} \sigma(p)^{2}\right\}^{-1}
$$

Parameters derived from the fits are given in table 3. Details of the Cox equation fits are given in table 2 .

Derived Enthalpies of Vaporization. Enthalpies of vaporization $\Delta_{1}^{9} H_{m}$ were derived from the Cox equation fits with the Clapeyron equation:

$$
d p / d T=\Delta_{1}^{g} H_{m} /\left(T \Delta_{1}^{g} V_{m}\right)
$$

where $\Delta_{1}^{g} V_{m}$ is the increase in molar volume from the liquid to the real vapor. Estimates of liquid-phase volumes were made with the extended corresponding-states equation of Riedel,(27) as formulated by Hales and Townsend.(28) Vapor-phase volumes were calculated with second virial coefficients estimated with the corresponding-states equation of Pitzer and Curl, (29) and third virial coefficients estimated with the corresponding-states method of Orbey and Vera. ${ }^{(30)}$ This formulation for third virial coefficients was applied successfully in analyses of the thermodynamic properties of benzene, toluene, and decane.(31) Third virial coefficients are required for accurate 
calculation of the gas volume for pressures greater than one bar. Derived enthalpies of vaporization and entropies of compression are reported in table 4.

\section{HEAT-CAPACITY CALORIMETRY}

2,3-Benzothiophene was studied previously by adiabatic heat-capacity calorimetry in the temperature range $12: 0330 K_{1}(5)$ and included replicate determinations of the enthalpy of fusion. The purpose of the new measurements described here was to extend the results for the liquid phase to higher temperatures. High-precision ( \pm 0.1 per cent) adiabaric calorimetry was used for measurements between $275 \mathrm{~K}$ and $500 \mathrm{~K}$, and differential-scanning calorimetry ( \pm 1.0 per cent) was used from $305 \mathrm{~K}$ to near the critical temperature $(764 \mathrm{~K})$. A melting study, performed as part of the adiabatic calorimetry experiments, was used to determine the sample purity and to check the accuracy of the enthalpy-of-fusion Jeterminations completed in the earlier $\left.{ }^{5}\right)$ study.

Crystallization and Melting Study by Adiabatic Calorimetry Crystallization of 2,3-benzothiophene was initiated by slowly cooling (approximately $2.5 \mathrm{mK}^{-1}$ ) the liquid sample. Complete crystallization was ensured by maintaining the sample under adiabaic conditions in the partially melted state (10 to 20 per cent liquid) for approximately $8 \mathrm{~h}$. No spontaneous warming, which would indicate incomplete crystallization, was observed in this time period. The sample was cooled at an effective rate of $3 \mathrm{mK} \cdot \mathrm{s}^{-1}$ to crystallize the remaining liquid. As a final step, the sample was thermally cycled between $<200 \mathrm{~K}$ and within $2 \mathrm{~K}$ of the triple-point temperature, where it was held for a mininum of $24 \mathrm{~h}$ to provide further tempering.

The triple-point temperature $T_{t p}$ and sample purity were determined by measurement of the equilibrium melting temperatures $T(F)$ as a function of fraction $F$ of the sample in the liquid state(32) for $F$ values between 0.3 and 0.8 . Equilibrium melting temperatures were determined by measuring temperatures at approximately 300 -s intervals for 0.75 to $1 \mathrm{~h}$ after an energy input and extrapolating to infinite time by assuming an exponential decay toward the equilibrium value. The observed temperatures at $1 \mathrm{~h}$ after an energy input were invariably within $3 \mathrm{mK}$ of the calculated equilibrium temperatures. No evidence for solid-soluole impurities was found. The mole fraction of impurities was calculated to be 0.0008 . The triple-point temperature $(304.48 \mathrm{~K})$ was in good accord with that found previolsily. (5) (Note: The value for $T_{t p}$ listed by Finke et al. $(5)$ is $304.50 \mathrm{~K}$, which is $304.48 \mathrm{~K}$, when converted to IPTS-68.) 
Phase Transformations and Enthalpy Measurements. Experimental molar enthalpy results are summarized in table 5 . The table includes both the enthalpy-of-fusion determination and single-phase measurements in the liquid phase, which served as checks on the integration of the heat-capacity results. Corrections for pre-melting caused by impurities were made in these evaluations. Results with the same series number in tables 5 and 6 were taken without interruption of adiabatic conditions.

Heat Capacity Measurements by Adiabatic Calorimetry. The experimental molar heat capacities under vapor-saturation pressure $C_{\text {sal,m }}$ determined by adiabatic calorimetry are listed in table 6. Values in table 6 were corrected for effects of sample vaporization into the gas space of the calorimeter. The tempcrature increments were small enough to obviate the need for corrections for non-linear variation of $\tau_{s a t, m}$. The precision of the heat-capacity measurements was approximately 0.05 per cent. The crystal-phase heat capacities in table 6 have not been corrected for pre-melting, but from the temperature increments provided an independent calcuiation can be made. For heat-capacity measurements in the liquid phase, equilibrium was reached in less than $1 \mathrm{~h}$. Equilibration times for the crystals were $2 \mathrm{~h}$ near $275 \mathrm{~K}$, and increased to $4 \mathrm{~h}$ at $280 \mathrm{~K}, 7 \mathrm{~h}$ at $290 \mathrm{~K}$, and $10 \mathrm{~h}$ at $300 \mathrm{~K}$.

\section{DIFFERENTIAL SCANNING CALORIMETRY}

Theoretical Background. The theoretical background for the determination of heat capacities at vapor-saturation pressure, $C_{s a t, m}$, with results obtained with a d.s.c. has been described. $(23,24)$ If two phases are present and the liquid is a pure substance, then the vapor presfure $p$ and the chemical potential $\mu$ are independent of the amount of substance $n$ and the cell volume $V_{x}$, and are equal to $p_{\text {sat }}$ and $\mu_{\text {sat }}$. The two-ph ise heat capacities at cell volume $V_{x}, C_{x, m}^{l l}$, can be expressed in terms of the temperature derivatives of these quantities:

$$
n C_{x, m^{\prime \prime}}^{\prime \prime}=-n\left(\partial^{2} \mu / \partial T^{2}\right)_{s a t}+V_{x}\left(\partial^{2} p / \partial T^{2}\right) s a t+\left\{\left(\partial V_{x} / \partial T\right)_{x}(\partial p / \partial T)_{s a t}\right\}
$$

The third term on the right-hand side of equation (7) includes the thermal expansion of the cell. In this research the thermal expansion of the cells was expressed as:

$$
V_{x}(T) / V_{x}(298.15 K)=1+a y+b y^{2}
$$

where, $y=(T-298.15) K, a=3.216 \times 10^{-5} K^{-1}$, and $b=5.4 \times 10^{-8} K^{-2}$.

$(\partial \mathrm{p} / \partial T)_{\text {sat }}$ can be calculated based on the vapor pressures measured in this research. Therefore, with a minimum of two different filing levels of the cell 
$\left(\partial^{2} p / \partial T^{2}\right)$ sat and $\left(\partial^{2} \mu / \partial T^{2}\right)$ sat can be determined. In this research three fillings were used. To obtain the saturation heat capacity $\mathrm{C}_{\text {sat.m }}$ at vapor pressures greater than $0.1 \mathrm{MPa}$, the limit where the celi is full of liquid is required; i.e., $\left(n / V_{x}\right)=\left\{1 / V_{m}(I)\right\}$ where $V_{m}(I)$ is the molar volume of the liquid:

$$
\lim _{\left(n / V_{x}\right) \rightarrow\left\{1 N_{m}(1)\right\}}\left(n C_{v, m}^{\prime \prime} / T\right)=V_{m}(I)\left(\partial^{2} p / \partial T^{2}\right)_{\text {Sát }}-n\left(\partial^{2} \mu / \partial T^{2}\right)_{\text {sat }} .
$$

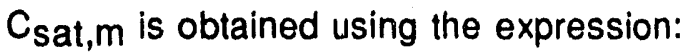

$$
\lim _{\left(n / V_{x}\right) \rightarrow\left\{1 N_{m}(1)\right\}}\left(n C_{V, m}^{\prime \prime}\right)=n\left[C_{s a t, m}-\left\{T(\partial p / \partial T)_{\text {sat }}\left(d V_{m}(I) / d T\right)\right\}\right] .
$$

Thus, reliable liquid density values are required also to determine $\mathrm{C}_{\mathrm{sat}, \mathrm{m}}$.

d.s.c. Measurement Results. Table 7 lists the experimental two-phase heat capacities $C_{x, m}^{\prime \prime}$ for 2,3-benzothiophene obtained for three cell fillings. Heat-capicities were determined at $20-\mathrm{K}$ intervals with a heating rate of $0.083 \mathrm{~K} \cdot \mathrm{s}^{-1}$ and a $120-\mathrm{s}$ equilibration period between heats. Sample decomposition precluded heat-capacity measurements above $750 \mathrm{~K}$.

By employing a single continuous heat at a heating rate of $0.333 \mathrm{~K} \cdot \mathrm{s}^{-1}$, sample decomposition was greatly reduced, and the abrupt decrease in heat capacity associated with the conversion from the two-phases io one-phase was observed. Temperatures at which conversion to the single phase occurred were measured in this way for eight cell fillings. Table 8 reports the density, obtained from the mass of sample and the cell volume calculated with equation (8), and the measured temperatures at which conversion to a single phase was observed. A critical temperature of $(764 \pm 2) \mathrm{K}$ and a corresponding critical density of $(354 \pm 7) \mathrm{kg} \cdot \mathrm{m}^{-3}$ were derived graphically for 2,3-benzothiophene with these results, as seen in figure 1. Results of measurements on benzene and decane performed as "proof-of-concept" measurements for these procedures have been reported.(23) The rapid heating method was used previously for criticaltemperature and critical-density determinations for dibenzothiophene.(33)

Simultaneous Fit of Vapor-pressure and Two-phase Heat-capacity Results. The critical pressure for 2,3-benzothiophene was not measured directly, but was estimated by means of simultaneous non-linear least-squares fits using the vapor pressures listed in table 2 and the $C_{x, m}^{\prime \prime}$ value:; given in table $7 . C_{s a t, m}$ values were derived using results 


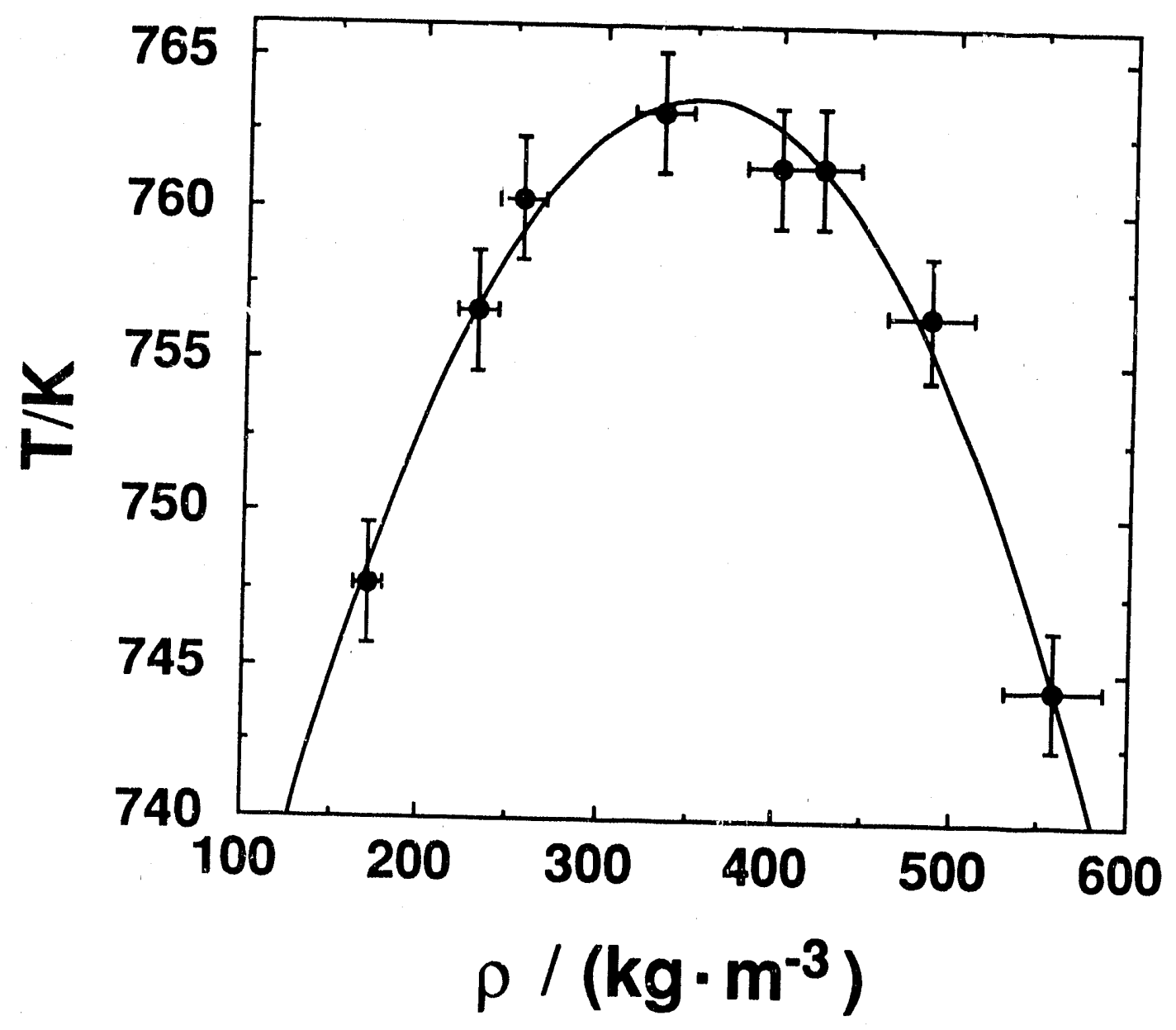

FIGURE 1. Vapor-liquid coexistence region for 2,3-benzothiophene. The crosses span the range of uncertainty. 
of the fit and equation (10). Experimental $C_{x, m}^{\prime \prime}$ were converted to $q_{v, m}^{\prime \prime}$ values by means of equation (8) for the cell expansion and the vapor-pressure fit described below for $(\partial \mathrm{p} / \partial \mathrm{T})$ sat. The values of $\mathrm{C}_{v, m}^{\prime \prime}$ were used to derive functions for $\left(\partial^{2} \mathrm{p} / \partial T^{2}\right)_{s}$ at and $\left(\partial^{2} \mu / \partial T^{2}\right)$ sat. The Cox equation(26) was used to represent the vapor pressures in the form:

$$
\ln \left(p / p_{C}\right)=\left(1-1 / T_{r}\right) \exp \left(A+B T_{r}+C T_{r}^{2}\right)
$$

with $T_{r}=T / T_{C}$, where $T_{C}$ and $p_{C}$ are the critical temperature and critical pressure. The critical pressure was included as a variable in the non-linear least-squares analysis. The functional form chosen for variation of the second derivative of the chemical potential with temperature was:

$$
\left(\partial^{2} \mu / \partial T^{2}\right)_{s a t}=\sum_{i=0}^{n} b_{i}\left(1-T / T_{c}\right)^{!}
$$

[For compounds where sufficient information was available to evaluate reliably $\left(\partial^{2} \mu / \partial r^{2}\right)$ sat (e.g., benzene(34)), four terms (i.e, expansion to $n=3$ ) were required to represent the function. Thus, four terms were used in this research.] In these fits the sum of the weighted squares in the following function was ininimized:

$$
\Delta=q_{v}^{\prime \prime}, m^{/ R}-\left\{V_{m}(I) T / n R\right\}\left(\partial^{2} p / \partial T^{2}\right)_{s a t}+(T / R)\left(\partial^{2} \mu / \partial T^{2}\right) \text { sat. }
$$

For the vapor-pressure fits, the functional forms of the weighting iactors used have been reported.(19) Within the heat-capacity results, the weighting factors were proportional to the square of the mass of sample used in the measurements. A weighting factor of 20 was used to increase the relative weights of the vapor-pressure rneasurements in the fit. The weighting fartor reflects the higher precision of the vapor-pressure values relative to the experimental heat capacities. Table 9 lists the coefficients determined in the non-linear least-squares fit.

values of $C_{s a t, m}$ were derived from $\mathcal{Q}_{v, m}^{\prime \prime}(\rho=\rho$ sat) with the densities obtained from the corresponding-states equation in the form:(28)

$\left(\rho / \rho_{C}\right)=1.0+0.85\left\{1.0-\left(T / T_{C}\right)\right\}+(1.692+0.986 \omega)\left\{1.0-\left(T / T_{C}\right)\right\}^{1 / 3}$,

with $\rho_{C}=354 \mathrm{~kg} \cdot \mathrm{m}^{-3}, T_{C}=764 \mathrm{~K}$, and the acentric factor $\omega=0.306$. The acentric factor is defined as $\left\{-\lg \left(p / p_{c}\right)-1\right\}$, where $p$ is the vapor pressure at $T_{r}=0.7$ and $p_{c}$ is the critical pressure. The Cox equation coefficients given in table 9 were used to 
calculate $p$. The results for $q_{, m}^{\prime \prime}(\rho=\rho$ sat $) / R$ and $C_{\text {sat, }} / R$ are reported in table 10 . The estimated uncertainty in these values is 1 per cent.

\section{THERMODYNAMIC PROPERTIES IN THE CONDENSED STATE}

Condensed-phase entropies and enthalpies relative to those of the crystals at $T \rightarrow O$ for the liquid phase under vapor-saturation pressure are lișted in table 11. These were derived by integration of the smoothed heat capacities for the liquid phase listed in tables 6 and 10, logether with the absolute entropy $(5)$ and enthalpy $(35,36)$ reported by Finke et al. (5) for the liquid at $T_{t p}$. The heat capacities were smoothed with cubic-spline functions by least-squares fits to six points at a time and by requiring continuity in value, slope, and curvature at the junction of successive cubic functions. Due to limitations in the spline-function procedure, some acceptable values from tables 6 and 10 were not included in the fit, while in other regions graphical values were introduced to ensure that the second derivative of the heat capacity with respect to temperature was a smooth function of temperature.

Finke et al. (5) reported their results in terms of the 1948 temperature scale. Except for the value of the triple-point temperature, thiese results were not converted to IPTS-68. The conversion was not justified in view of large uncertainties in heat-leak corrections in the vicinity of phase transitions. $(5,36)$ The absolute entropy and enthalpy for the triple-point temperature reported by Finke et al.(5) were assigned an uncertainty of 0.2 per cent of their values for all calculations reported here.

\section{THERMODYINAMIC PROPERTIES IN THE IDEAL-GAS STATE}

Enthalpies and entropies at selected temperatures for the ideal gas were calculated using values in tables 4 and 11 and are listed in columns 2 and 4 of table 12. The derived ideal-gas enthalpies and entropies were combined with an enthalpy of formation $36.635 \pm 0.97 \mathrm{~kJ} \mathrm{~mol}^{-1}$ for the reaction:

$$
8 \mathrm{C}(\mathrm{cr}, \text { graphite })+3 \mathrm{H}_{2}(\mathrm{~g})+0.5 \mathrm{~S}_{2}(\mathrm{~g})=\mathrm{C}_{8} \mathrm{H}_{6} \mathrm{~S}(\mathrm{cr}) \text {, }
$$

to calculate the enthalpies, entropies, and Gibbs energies of formation listed in columns 6,7 , and 8 , respectively, of table 12 . The enthalpy of formation is based on an energy of combustion for the crystalline phase determined by Good(6) and the enthalpies of formation for $\mathrm{S}_{2}(\mathrm{~g}), \mathrm{CO}_{2}(\mathrm{~g}), \mathrm{H}_{2} \mathrm{O}(\mathrm{l})$, and $\mathrm{H}_{2} \mathrm{SO}_{4} \cdot 115 \mathrm{H}_{2} \mathrm{O}$ selected by CODATA.(37) Enthalpies and entropies for equilibrium hydrogen and $S_{2}(g)$ were determined from JANAF tables. (38) Values for graphite were determined with the polynomial(39) used to calculate the values from $298.15 \mathrm{~K}$ to $6000 \mathrm{~K}$ listed in the JANAF tables. All 
uncertainties in table 12 represent one standard deviation, and do not include uncertainties in the properties of the elements.

\section{SUBLIMATION PRESSURES}

The "third-law" method(24,33) was employed to calculate sublimation pressures for 2,3-benzothiophene from $270 \mathrm{~K}$ to the triple-point temperature. The "third-law" values weie calculated from the tabulated thermodynamic functions of the solid and the liquid (table 11), and extrapolated vapor pressures of the liquid phase, calculated with the Cox coefficients listed in table 3 . The sublimation pressures were represented by the equation:

$$
\ln \left(\mathrm{p} / \mathrm{p}_{\mathrm{o}}\right)=30.15-7.909 \times 10^{3}(\mathrm{~T} / \mathrm{K})^{-1}-3.4 .32 \times 10^{4}(\mathrm{~T} / \mathrm{K})^{-2},
$$

in the temperature region $270 \mathrm{~K}$ to $304.48 \mathrm{~K}$ with $\mathrm{p}_{\mathrm{o}}=1 \mathrm{~Pa}$.

\section{Discussion}

\section{COMPARISON WITH LITERATURE HEAT CAPACITIES}

The only measurements of the heat capacities of 2,3-benzothiophene found in the literature were those published by Finke et al.,(5) and used in this research to calculate the entropy and enthalpy of the liquid at $T_{\text {tp }}$ relative to the crystals at $T \rightarrow 0$. Deviations of the earlier results from those of the present study are shown in figure 2 for the temperature region of overlap $(275 \mathrm{~K}$ to $330 \mathrm{~K})$. The accuracy claimed by Finke et al. (5) was 0.2 per cent of the heat capacity. The deviations are in accord with the claimed accurary, except near $T_{t p}(304.48 \mathrm{~K})$ for a single solid-phase value, which is high because Finke et al. did not apply pre-melting corrections. To eliminate ambiguities involved with pre-melting near $T_{\text {tp }}$, the differences between the enthalpy of the liquid at $T_{t p}$ and that of the crystals at $290 \mathrm{~K}$ were compared. The enthalpy measured by Finke et al. was 0.15 per cent higher than that found in this research. The difference is within the expected range of uncertainty.

\section{COMPARISON WITH LITERATURE VAPOR PRESSURES}

Results for the liquid phase. Vapor-pressure measurements have been reported for the liquid(7-9) and solid(7) phases of 2,3-benzothiophene. Figure 3 is a deviation plot for those measurements above the triple-point temperature relative to those of this research. Vapor-pressure values for the liquid phase listed by Edwards and Prausnitz $(7)$ are within five per cent of the values of this research. This is in accord with the accuracy claimed by the authors. 


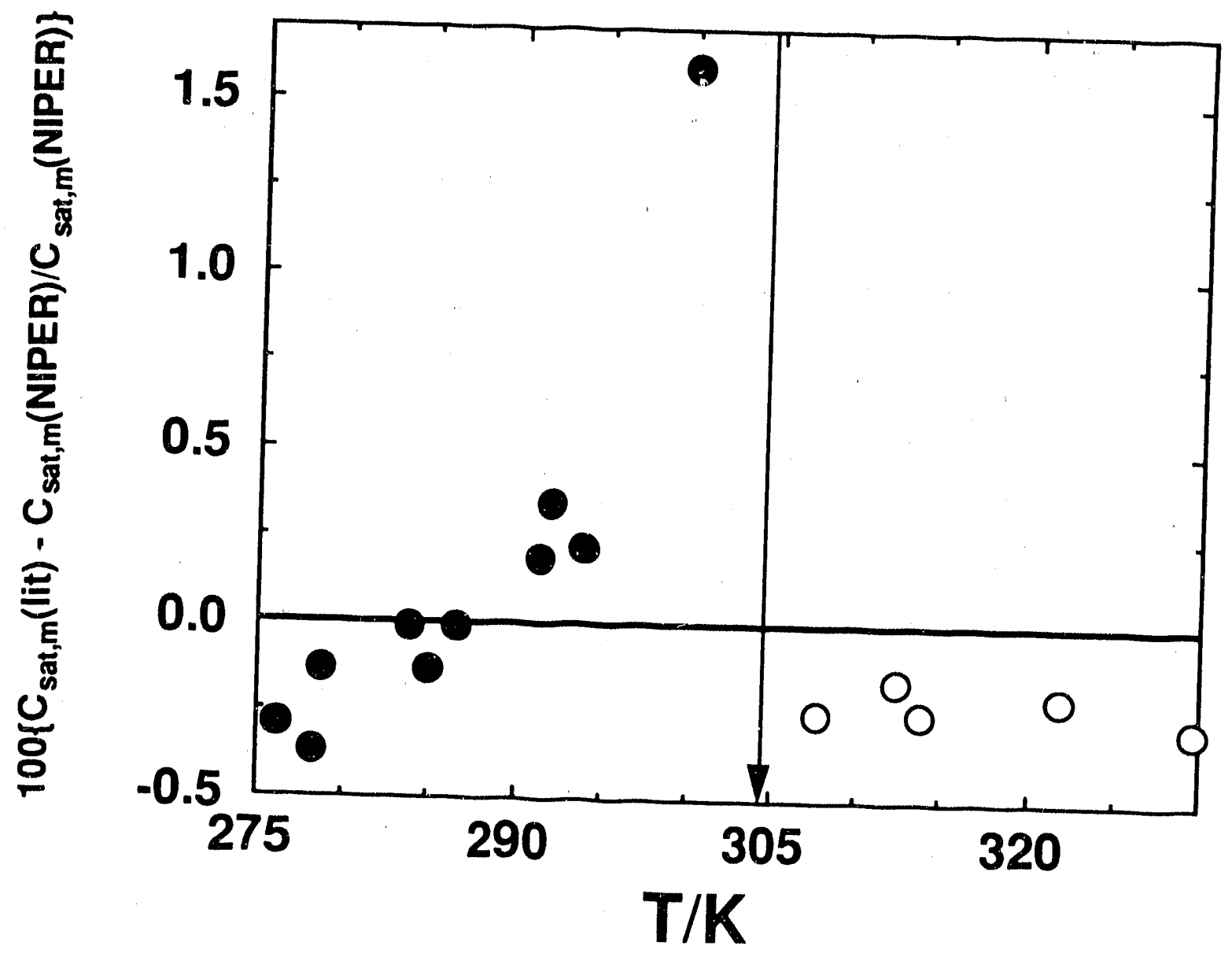

FIGURE 2. Deviation plot for 2,3-benzothiophene heat capacities. $C_{s a t, m}$ (lit) values are

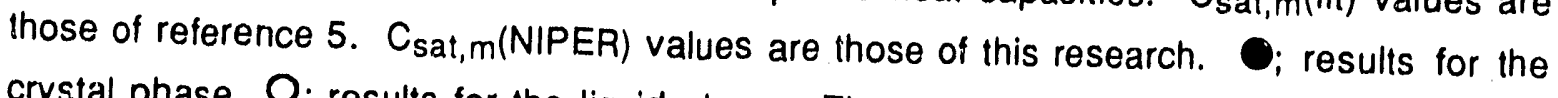
crystal phase, $\mathrm{O}$; results for the liquid phase. The vertical line indicates $T_{t p}$. 


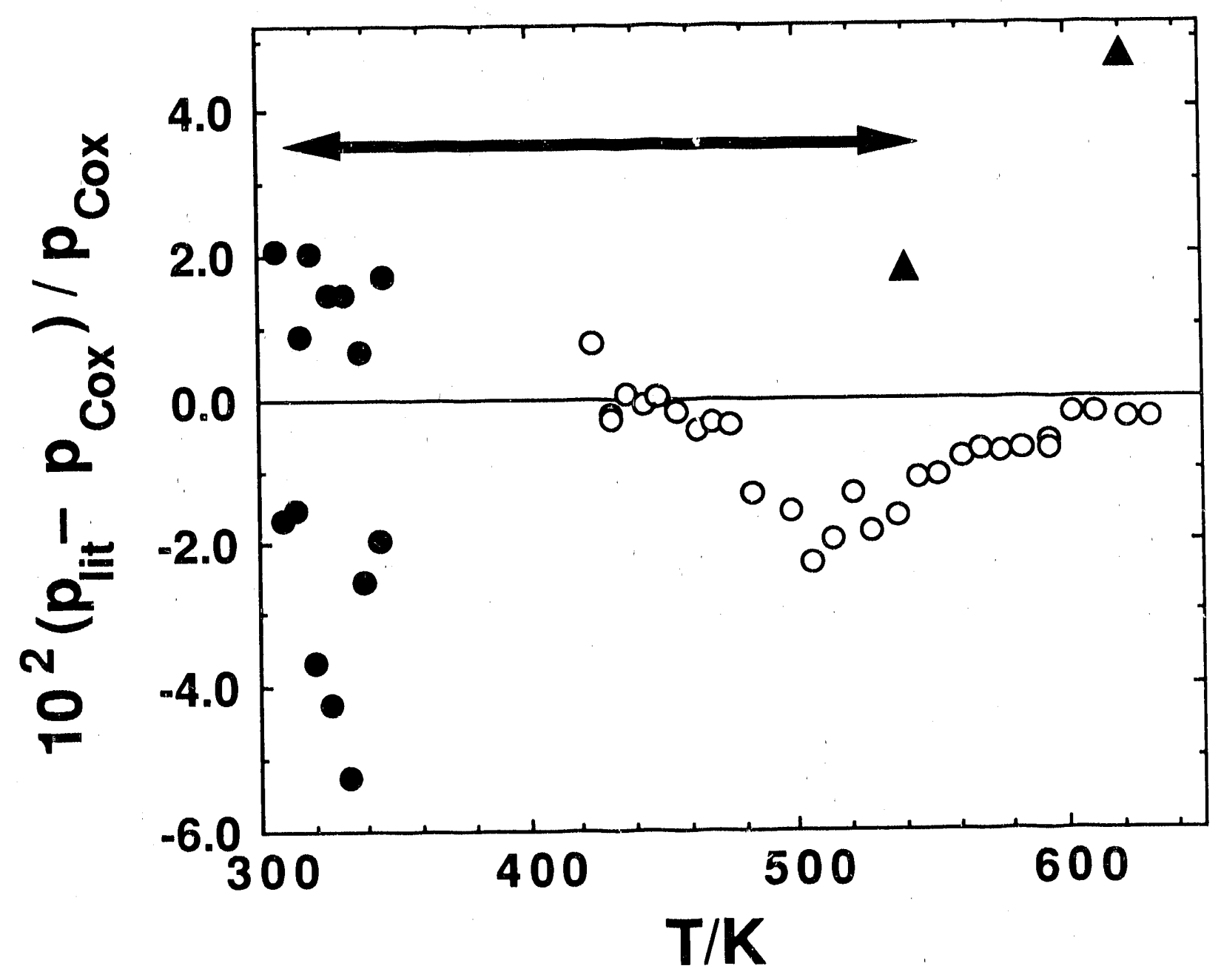

FIGURE 3. Deviation plot for literature vapor pressures of 2,3-benzothiophene relative to those of this research. PCox was calculated with the Cox-equation coefficients listed in table 3. The double-headed arrow indicates the range of experimental measurements of this research. $\mathrm{O}$, Wieczorek and Kobayashi;(8) $\mathbf{\Delta}$, Sebastian et al.;(9) $\bullet$, Edwards and Prausnitz.(7) 
Wieczorek and Kobayashi( $(8)$ measured vapor pressures of 2,3-benzothiophene with a claimed uncertainty of 0.015 per cent in the pressure. Deviations from results of the present research are between 1 and 2 per cent. No reason for the difference is apparent. In spite of the high. accuracy claimed by the research group of Kobayashi, deviations from NIPER results are often large. $(24,33,40,41)$

Sebastian et al.(9) measured the vapor pressure of 2,3-benzothiophene at two temperatures as part of a hydrogen-solubility study. Observed differences from the present results are in accord with the expected accuracy of their measurement method (i.e., within several per cent).

Results for the solid phase. Edwards and Prausritz (7) reported sublimation pressures for 2,3-benzothiophene from $272.8 \mathrm{~K}$ to $302.6 \mathrm{~K}$ ( $T_{\text {tp }}=304.48 \mathrm{~K}$ ). Percentage differences from values calculated in this research with equation (16) are shown in figure 4 as unfilled circles. Deviations vary smoothly from roughly 5 per cent high near the triple-point temperature to 45 per cent high near $270 \mathrm{~K}$. This is in stark contrast to their results for dibenzothiophene,(7) which were 8 per cent low on average relative to sublimation pressures calculated in research at NIPER.(33) (Edwards and Prausnitz use a gas-saturation technique to measure their sublimation pressures. It was postulated $(33)$ that the 8 per cent difference may have been due to incomplete saturation of the carrier gas.)

The percentage deviation of the results of Edwards and Prausnitz $(7)$ from the extrapolated vapor pressures for the liquid phase of this research is shown, also, in figure 4 . The deviations are in accord in both magnitude and sign with those observed for the sublimation pressures of dibenzothiophene. Such a result is possible, if Edwards and Prausnitz completed their measurements on a supercooled-liquid sample of 2,3-benzothiophene rather than on the crystals.

\section{COMPARISON WITH LITERATURE ENTHALPIES OF SUBLIMATION}

The enthalpy of sublimation at $298.15 \mathrm{~K}$ for 2,3-benzothiophene was determined calorimetrically by Sabbah. $(42,43)$ His values range from $65.1 \mathrm{~kJ} \cdot \mathrm{mol}^{-1}$ to $67.1 \mathrm{~kJ} \cdot \mathrm{mol}^{-1}$. These are in fair accord with the value derived in this research $\left(67.3 \mathrm{~kJ} \cdot \mathrm{mol}^{-1}\right)$ obtained by differencing at $298.15 \mathrm{~K}$ the ideal-gas enthalpy (table 12) and the enthalpy of the crystals $\left(27.98 \mathrm{~kJ} \cdot \mathrm{mol}^{-1}\right) \cdot(35,36)$

An enthalpy of sublimation was calculated from the results of Edwards and Prausnitz $(7)$ with a straight-line fit of their values plotted as $\mathrm{lg}(\mathrm{p} / \mathrm{Pa})$ against $1 / \mathrm{T}$. The derived value $\left(60.9 \mathrm{~kJ} \cdot \mathrm{mol}^{-1}\right)$ is approximately 10 per cent lower than that of this 


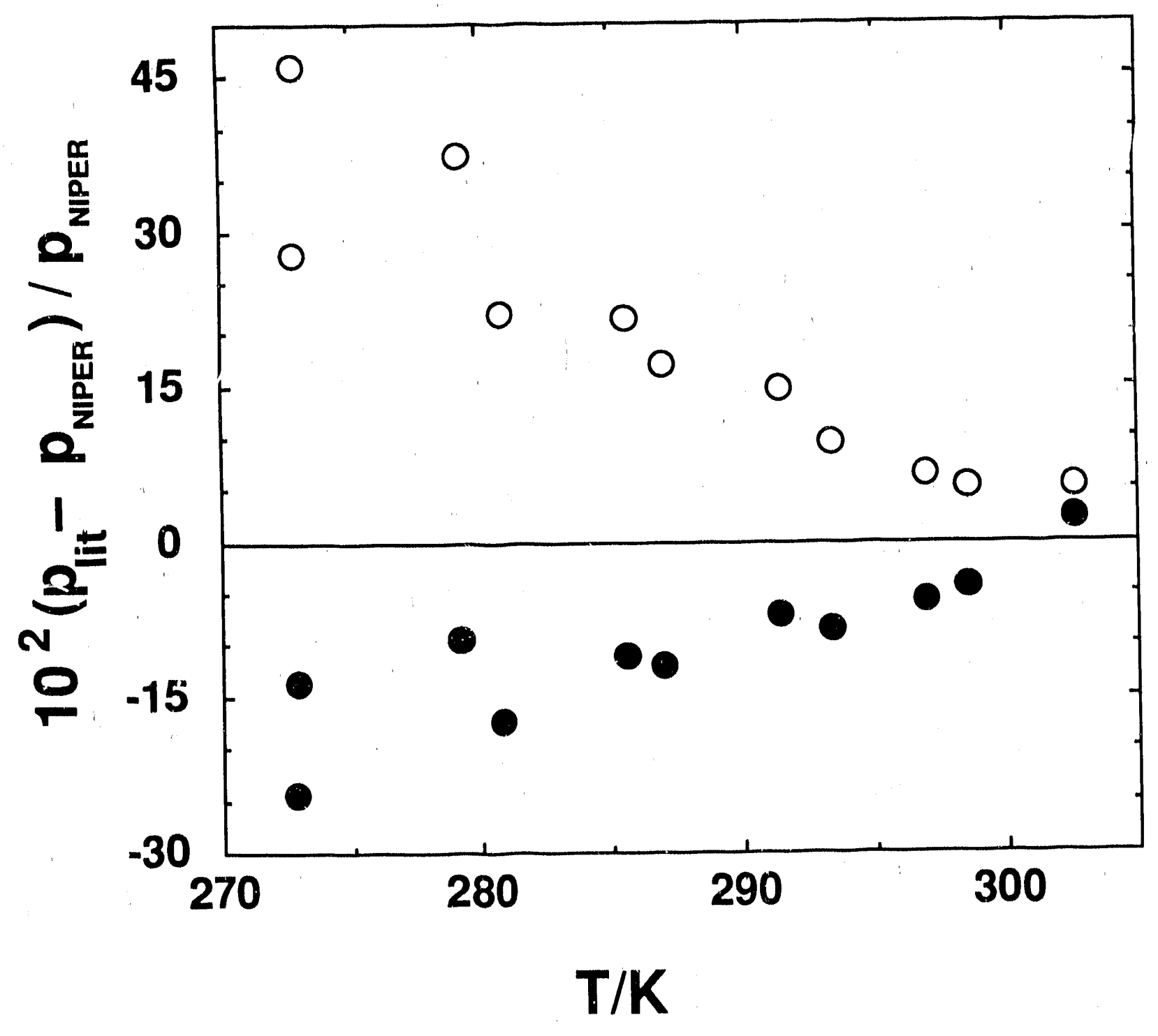

FIGURE 4. Deviation plot for sublimation pressures of Edwards and Prausnitz $(7)$ fnr 2,3-benzothiophene relative to those of this research. O, PNIPER was calculated with equation (16) (solid-phase values); P PNIPER was calculated with the Cox-equation coefficients listed in table 3 (llquid-phase values). 
research. This is in contrast to the good accord ( 1.5 per cent difierence) observed for dibenzothiophene.(33) This is further evidence that the sample used by Edwards and Prausnitz may have been the super-cooled liquid.

\section{COMPARISON WITH LITERATURE DENSITIES}

Densities for 2,3-benzothiophene were measured by Haines et al. (44) and Auwers, (45) and estimated by Gray(46) with $T_{b}$ and the molecular mass. Also, the liquid-phase density was measured in this research with the volume and mass of sample used in the adiabatic heat-capacity calorimetry studies. The measured value was $1120 . t 30 \mathrm{~kg} \cdot \mathrm{m}^{-3}$ at $332 \mathrm{~K}$.

The measured and estimated values are compared in figure 5 with values calculated with equation (14) and the critical constants and acentric factor listed in table 9. The uncertainties in the values calculated with equation (14) are approximately 2 per cent. The results reported by Auwers $(45)$ and the estimate by Gray (46) are in accord with this. However, Haines et al.(44) reported much higher values with a clained uncertainty of only 0.01 per cent.

The measurements by Haines et al.(44) were completed as part of API Research Project $48 \mathrm{~A}$. The sample used in the heat-capacity studies by Finke et al.(5) was prepared, also, in this project. Haines ef al. reported stability problems with their samples of 2,3-benzothiophene, which have not been observed with any of the samples at NIPER. (Haines et al. ${ }^{(44)}$ reported that one of their 0.051 samples, sealed in vacuo, "exploded violently" after six months.) The unusually large differences between the densities measured by Haines et al. and those calculated with equation (14) may be related to these stability problems, though no clear evidence for this exists. Highprecision density measurements with a vibrating-tube densimeter are planned at NIPER to resolve the discrepancy.

\section{COMPARISON VVITH LITERATURE IDEAL-GAS ENTROPIES DERIVED FROM SPECTROSCOPY}

Mille et al.(47) published complete spectral assignments for wavenumber values from $200 \mathrm{~cm}^{-1}$ to $1650 \mathrm{~cm}^{-1}$ for 2,3-benzofuran and 2,3-benzothiophene. These results were augmented with results obtained at NIPER(48) for wavenumbers above $3000 \mathrm{~cm}^{-1}$, to provide complete assignments for the molecules. The fundamental vibrations of these molecules do not have wavenumber values between $1650 \mathrm{~cm}^{-1}$ and $3000 \mathrm{~cm}^{-1}$. The moment of inertia product $\left(1.6013 \times 10^{-133} \mathrm{~kg}^{3} \cdot \mathrm{m}^{6}\right)$ was calculated with the structure published by Hartford et al.(49) The rigid-rotor/harmonicoscillator approximation was used to calculate the ideal-gas entropies for the 


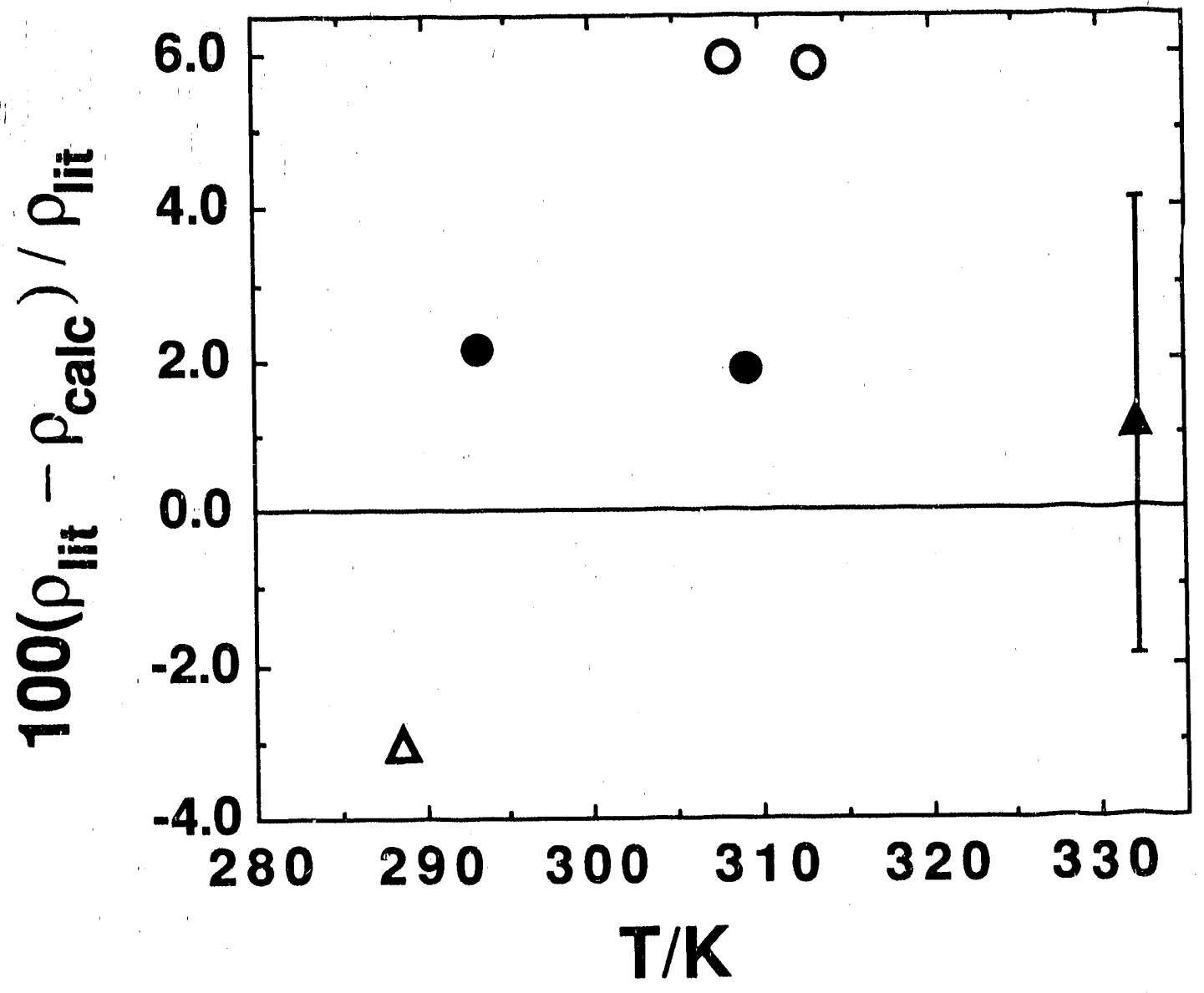

FIGURE 5. Deviation plot for 2,3-benzothiophene densities. $\odot$, Auwers; (45) $\mathbf{O}$. Haines et al.;(44) $\boldsymbol{\Delta}$, Gray; ${ }^{(46)} \Delta$; measured as part of the heatcapacity study of this research. See text. 
temperature range studied calorimetrically in this research. Uncertainties in the wavenumber values above $3000 \mathrm{~cm}^{-1}$ have a negligible impact on the precision of the calculated entropies.

Differences between the spectroscopic and calorimetrically-derived ideal-gas entropies are shown in figure 6. Values based on the results of Mille et al.(47) range from $0.5 \mathrm{R}$ to $1.5 \mathrm{R}$ low relative to the calorimetric values. This is nearly identical to the results obtained previously for 2,3-benzofuran.(50) In that case, Mille et al. listed a single mode below $400 \mathrm{~cm}^{-1}$, while Collier(51) and Smithson et al.(52) showed that two modes were present (at $211 \mathrm{~cm}^{-1}$ and $246 \mathrm{~cm}^{-1}$ ). Ideal-gas entropies based on the results of Collier(51) were in excellent accord with the calorimetric results for 2,3-benzofuran.

Mille ef al.,(47) also listed a single mode below $400 \mathrm{~cm}^{-1}$ for 2,3-benzothiophene. Recent unpublished gas-phase spectra at NIPER(48) show two bands below $400 \mathrm{~cm}^{-1}$, in analogy to the 2,3-benzofuran results. Complete assignment of the 2,3-benzothiophene spectra is being completed at NIPER within the Basic Energy Sciences project, "Thermodynamic Properties by Non-Calorimetric Methods." Much improved agreement between the spectroscopy and calorimetry-based calculations is expected.

\section{COMPARISON WITH LITERATURE CRITICAL PROPERTIES}

The values published in this report are the first for 2,3-benzothiophene. No experimental critical-proserty values were found in the literature. Table 13 shows a comparison of the experimental results with values estimated by the group-contribution methods of Lydersen,(53) Somayajulu, (54) and Joback. (55) The Lydersen parameters were published in 1955.(53) Joback(55) and Somayajulu(54) made use of the modern critical-property database to modify the Lydersen equations and expand the applicability of the approach. For the cilical pressure, the revised procedures provide an improved estimate. The parameters of Somayajulu(54) provide an improved estimate of the critical temperature. 


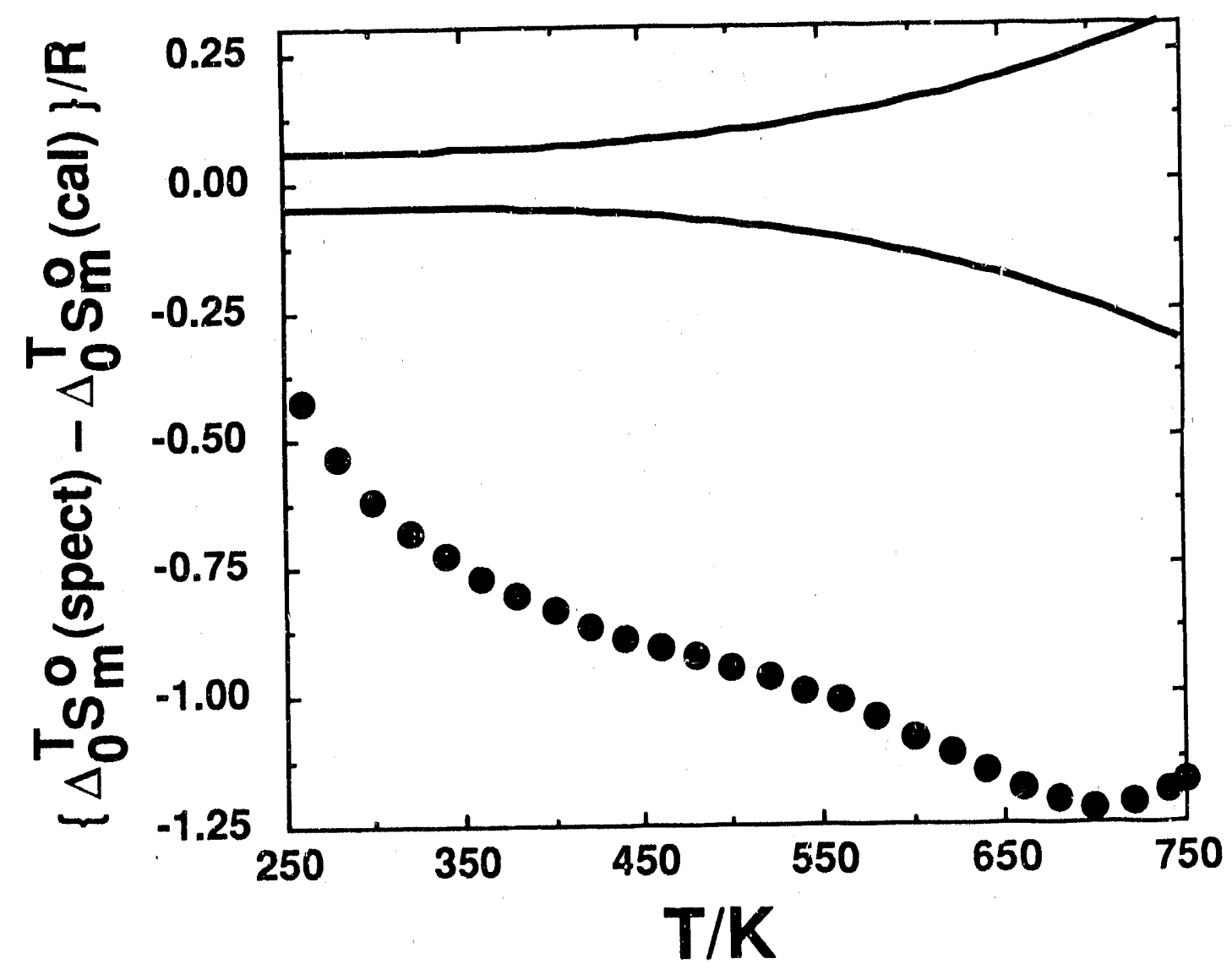

FIGURE 6. Deviation of ideal-gas entropy values calculated from spectroscopically determined vibrational frequencies and statistical mechanics (spect) from the calorimetrically (cal) derived values of this research. The curved lines represent the uncertainty limits of the calorimetric results (one standard deviation). The curve defined by 2 is based on the spectroscopic results of Mille et al.(47) 


\section{Summary and Conclusions}

- Gibbs energies of formation in the ideal-gas phase for 2,3-benzothiophene from $260 \mathrm{~K}$ to near $T_{c}$ are reported for the first time. These are required for a thermodynamic analysis of the 2,3-benzothiophene/hydrogen reaction network. This analysis will be published in an upcoming topical report. The value of the data in design and processing operations will be discussed then.

- Experimental critical properties for 2,3-benzothiophene, together with recent results published by the NIPER Thermodynamics Group for dibenzothiophene, provide an excellent foundation for the prediction of properties for numerous polycyclic sulfur-containing nolecules.

- Literature densities for 2,3-oenzothiophene are discordant. New reliable experimental determinations are needed.

- A published vibrational assignment for 2,3-benzothiophene is in error with regard to assignment of the lowest-wavenumber modes. A new assignment is being developed at NIPER as part of a research project for the Department of Energy/Office of Energy Research. 


\section{References}

1. Gates, B. C.; Katzer, J. R.; Schult, G. C. Chemistry of Catalytic Processes. McGraw-Hill: New York. 1979. Chap. 5.

2. Zuražil, M. Appl. Catalysis 1982, 4, 107.

3. Benson, S. W. Thermochemical Kinetics. 2nd edition. Wiley: New York. 1976.

4. Reid, R. C.; Prausnitz, J. M.; Poling, B. E. The Properties of Liquids and Gases. 4th edition. McGraw-Hill: New. York. 1987.

5. Finke, H. L.; Gross, M. E.; Messerly, J. F.; Waddington, G. J. Am. Chem. Soc. $1954,76,854$.

6. Good, W. D. J. Chem. Eng. Data 1972, 17, 158.

7. Edwards, D. R.; Prausnitz, J. M. J. Chem. Eng. Data 1981, 26, 121.

8. Wieczorek, S. A.; Kobayashi, R. J. Chem. Eng. Data 1980, 25, 302.

9. Sebastian, H. M.; Simnick, J. J.; Lin, H. M.; Chao, K. C. Can. J. Chem. Eng. 1978, $56,743$.

10. Commission on Atomic Weights and Isotopic Abundances. Pure Appl. Chem. 1983, $55,1101$.

11. Cohen, E. R.; Taylor, B. N. J. Phys. Chem. Ref. Data 1988, 17, 1795.

12. Metrologia 1969, 5, 35.

13. Swietoslawski, W. Ebulliometric Measurements. Reinhold: New York. 1945.

14. Osborn, A. G.; Douslin, D. R. J. Chem. Eng. Data 1966, 11, 502.

15. Chirico, R. D.; Nguyen, A..; Steele, W. V.; Strube, M. M.; Tsonopoulos, C. J. Chem. Eng. Data 1989, 34, 149.

16. Antoine, C. Comp. Rend. Acad. Sci. 1888, 107, 681.

17. Douslin, D. R.; McCullough, J.P. U. S. Bureau of Mines. Report of Investigation 6149, 1963, pp. 11.

18. Douslin, D. R.; Osborn A. G. J. Sci. Instrum. 1965, 42, 369.

19. Steele, W. V.; Archer, D. G.; Chirico, R. D. ; Collier, W. B.; Hossenlopp, I. A.; Nguyen, A.; Sinith, N. K.; Gammon, B. E. J. Chem. Thermodynamics 1988, 20, 1233.

20. Huffman, H. M. Chem Rev. 1947, 40, 1.

21. Ruehwein, R. A.; Huffman, H. M. J. Am. Chem. Soc. 1943, 65, 1920.

22. Scott, D. W.; Douslin, D. R.; Gross, M. E.; Oliver, G. D.; Huffman, H. M. J. Am. Chem. Soc. 1952, 74, 883.

23. Knipmeyer, S. E.; Archer, D. G.; Chirico, R. D.; Gammon, B. E.; Hossenlopp, I. A.; Nguyen, A.; Smith, N. K.; Steele, W. V.; Strube, M. M. Fluio Phase Equilibria $1989,52,185$.

24. Chirico, R. D.; Knipmeyer, S. E.; Nguyen, A.; Steele, W. V. J. Chem. Thermodynamics 1989, 21, 1307.

25. Scott, D. W.; Osborn, A. G. J. Phys. Chem. 1979, 83, 2714.

26. Cox, E. R. Ind. Eng. Chem. 1936, 28, 613.

27. Riedel, L. Chem.-Ing.-Tech, 1954, 26, 259.

28. Hales, J. L.; Townsend, R. J. Chem. Thermodynamics 1972, 4, 763.

29. Pitzer, K. S.; Curl, R. F. Jr. J. Am. Chem. Soc. 1957, 79, 2369.

30. Orbey, H.; Vera, J. H. AlChE J. 1983, 29, 107.

31. Steele, W. V.; Chirico, R. D. To be published. 
32. McCullough, J. P.; Waddington, G. Anal. Chim. Acta 1957, 17, 80.

33. Chirico, R. D.; Knipmeyer, S. E.; Nguyen, A.; Steele, W. V. J. Chem. Thermodynamics. In press

34. Goodwin, R. D. J. Phys. Chem. Ref. Data 1988, 17, 1541.

35. Unpublished. This value was not published in reference 5 , although it was calculated at that time.

36. Unpublished. Notebooks listing all the "raw" experimental-measurement results on all compounds studied in the Thermodynamics Research Laboratory since 1945 are available for consultation at NIPER.

37. Cox, J. D.; Wagman, D. D.; Medvedev, V. A.: editors. CLDATA Key Values for Thermodyramics. Hemisphere: New York. 1989.

38. Chase, M. W., Jr.; Davies, C. A.; Downey, J. R., Jr.; Frurip, D. J.; McDonald, R. A.; Syverud, A. N. JANAF Thermochemical Tables. 3rd edition. Supplement No. 1 to J. Phys. Chem. Ref. Data 1985, 14.

39. Chirico, R. D.; Archer, D. G.; Hossenlopp, I. A.; Nguyen, A.; Steele, W. V.; Gammon, B. E. J. Chem. Thermodynamics 1990, 22, 665.

40. Steele, W. V.; Chirico, R. D.; Hossenlopp, I. A.; Nguyen, A.; Smith, N. K.; Gammon, 8. E. J. Chem. Thermodynamics $1989,21,81$.

41. Chirico, R. D.; Gammon, B. E.; Knipmeyer, S. E.; Nguyen, A.; Strube, M. M.; Tsonopoulos, C.; Steele, W. V. J. Chem. Thermodynamics. In Press

42. Sabbah, R.; Antipine, I.; Coten, M.; Davy, L. Thermochim. Acta 1987, 115,

43. Sabbah, R. Bull. Soc. Chem. Fr. 1979, (9-10), 434.

44. Haines, W. E.; Helm, R. V.; Cook, G. L.; Ball, J. S. J. Phys. Chem. 1956, 60, 549.

45. Auwers, K. V. Ann. Chem. Liebigs 1915, 408, 212. As cited in The Coal Tar Data Book. The Coal Tar Research Association:Gomersal, Leeds, England. 1953.

46. Gray, R. D., Jr., 1984. Private communication cited in Tsonopoulos, C.; Heidman, J. L.; Hwang, S.C. Thermodynamic and Transport Properties of Coal
Liquids. Wiley:New York. 1986.

47. Mille, G.; Davidovics, G.; Chouteau, J. J. Chim. Phys. Physicochim. Biol. 1972,

48. Unpubli. hed data from the NIPER Spectroscopy Laboratory. 49. Hartford: $\Delta$ Jr.; Muirhead, A. R.; Lombardi, J. R. J. Mol. Spectr. 1970, 35,
199.

50. Steele, W. V.; Chirico, R. D. Thermodynamics and the Hydrodeoxygenation of 2,3-Benzofuran NIPER-457. Published by DOE Fossil Energy, Bartlesville Project Office. Available from NTIS Report No. DE-90000218, February 1990.

51. Collier, W. B. J. Chem. Phys. 1988, 88, 7295.

52. Smithson, T. L.; Shaw, R. A.; Wieser, H. J. Ch.

53. Lydersen, A. L. Estimation of Critical Properties of Organic Compounds by the Method of Group Contributions. College of Engineering; Engineering Experiment Station Report No. 3. University of Wisconsin: Madison, WI. 1955.

54. Somayajulu, G. R. J. Chem. Eng. Data 1989, 34, 106.

55. Joback, K. G. S. M. Thesis. Massachusetts Institute of Technology:Cambridge, MA. 1984. The equations and parameters are listed in reference 4. 
TABLE 1. Calorimeter and sample characteristics: $m$ is the sample mass; $V_{1}$ is the internal volume of the calorimeter; $T_{c a l}$ is the temperature of the calorimeter when sealed; $P_{c a l}$ is the pressure of the helium and sample when sealed; $r$ is the ratio of the heat capacity of the full calorimeter to that of the empty; $r_{\max }$ is the highest temperature of the measurements; and $\delta \mathrm{C} / \mathrm{C}$ is the vaporization correction; $x_{p r e}$ is the mole-fraction impurity used for pre-melting corrections

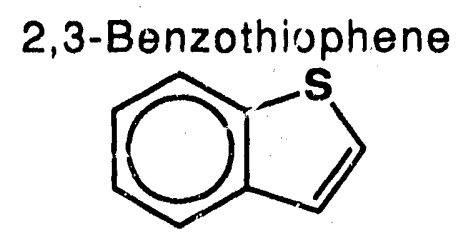

$\mathrm{m} / \mathrm{g}$

49.260

$V_{i}(298.15 \mathrm{~K}) / \mathrm{cm}^{3}$

61.00

$T_{\text {cal }} / \mathrm{K}$

299.2

$p_{\text {cal }} / \mathrm{kPa}$

6.75

$r\left(T_{\text {max }}\right)$

3.1

$r_{\min }$

2.8

$10^{2}(\delta \mathrm{C} / \mathrm{C})_{\text {max }}$

0.165

xpre

0.00085 
TABLE 2. Summary of vapor-pressure results for 2,3-benzothiophene: IP refers to measurements performed with the inclined-piston gauge; water or decane refers to which material was used as the standard in the reference ebulliometer; $T$ is the temperature of the experimental inclined-piston pressure gauge measurements or, for ebulliometric measurements, of the condensation temperature of the sample; the pressure $p$ for ebulliometric measurements was calculated from the condensation temperature of the reference substance; $\Delta p$ is the difference of the calculated value of pressure from the observed value of pressure; $\sigma(p)$ is the propagated error calculated from equations (1) and (2); $\Delta T$ is the difference between the boiling and condensation temperatures ( $T_{\text {boil }}-T_{\text {cond }}$ ) for the sample in the ebulliometer.

\begin{tabular}{|c|c|c|c|c|c|}
\hline Method & $\frac{T}{K}$ & $\frac{p}{k P a}$ & $\frac{\Delta p}{k P a}$ & $\frac{\sigma(p)}{k P a}$ & $\frac{\Delta T}{K}$ \\
\hline IP & 309.999 & 0.0659 & -0.0002 & 0.0002 & \\
\hline IP & 320.001 & 0.1278 & -0.0003 & 0.0002 & \\
\hline$I P$ & 329.997 & 0.2367 & -0.0004 & 0.0002 & \\
\hline IP & 339.996 & 0.4200 & -0.0003 & 0.0003 & \\
\hline IP & 349.992 & 0.7168 & -0.0004 & 0.0003 & \\
\hline IP & 359.997 & 1.1812 & -0.0008 & 0.0004 & \\
\hline IP & 370.003 & 1.8866 & -0.0002 & 0.0005 & \\
\hline decane & 371.302 & 2.0000 & -0.0005 & 0.0001 & 0.041 \\
\hline decane & 377.838 & 2.6660 & 0.0000 & 0.0002 & 0.026 \\
\hline IP & 380.003 & 2.9241 & -0.0004 & 0.0007 & \\
\hline decane & 387.557 & 3.9999 & -0.0001 & 0.0002 & 0.021 \\
\hline decane & 394.819 & 5.3330 & 0.0001 & 0.0003 & 0.013 \\
\hline decane & 405.623 & 7.9989 & 0.0014 & 0.0004 & 0.009 \\
\hline decane & 413.740 & 10.666 & 0.002 & 0.001 & 0.005 \\
\hline decane & 420.307 & 13.332 & 0.002 & 0.001 & 0.004 \\
\hline tecane & 427.130 & 16.665 & 0.002 & 0.001 & 0.003 \\
\hline decane & 432.803 & 19.933 & 0.002 & 0.001 & 0.001 \\
\hline decane & 440.273 & 25.023 & 0.002 & 0.001 & 0.000 \\
\hline water & $440.271 \quad a$ & 25.023 & 0.003 & 0.001 & 0.000 \\
\hline water & 447.798 & 31.177 & 0.001 & 0.002 & -0.003 \\
\hline water & 455.375 & 38.565 & -0.002 & 0.002 & -0.006 \\
\hline
\end{tabular}


TABLE 2. Continued

\begin{tabular}{lccccc}
\hline Method & $\frac{T}{\mathrm{~K}}$ & $\frac{\mathrm{p}}{\mathrm{kPa}}$ & $\frac{\Delta \mathrm{p}}{\mathrm{kPa}}$ & $\frac{\sigma(\mathrm{p})}{\mathrm{kPa}}$ & $\frac{\Delta T}{\mathrm{~K}}$ \\
\hline water & 463.007 & 47.375 & -0.009 & 0.002 & -0.003 \\
water & 470.688 & 57.817 & -0.010 & 0.003 & -0.004 \\
water & 478.422 & 70.120 & -0.012 & 0.003 & -0.006 \\
water & 486.209 & 84.533 & -0.009 & 0.004 & -0.005 \\
water & 494.048 & 101.325 & -0.006 & 0.004 & -0.005 \\
water & 501.944 & 120.79 & -0.01 & 0.01 & -0.005 \\
water & 509.894 & 143.25 & -0.00 & 0.01 & -0.006 \\
water & 517.891 & 169.02 & 0.00 & 0.01 & -0.005 \\
water & 525.947 & 198.49 & 0.01 & 0.01 & -0.005 \\
water & 534.050 & 232.02 & 0.02 & 0.01 & -0.006 \\
water & 542.207 & 270.02 & 0.02 & 0.01 & -0.006 \\
\hline
\end{tabular}

a The value at this temperature was not included in the fit. 
TABLE 3. Cox-equation coefficients for 2,3-benzothlophene

$\begin{array}{lc}T_{\text {ref }} / \mathrm{K} & 764 \\ \mathrm{P}_{\text {ref }} / \mathrm{kPa} & 47 \leqq 0 \\ \mathrm{~A} & 2.39909 \\ 10^{3} \mathrm{~B} & -1.64694 \\ 10^{6} \mathrm{C} & 1.50332 \\ \mathrm{~T} / \mathrm{Ka} & 310 \text { to } 542\end{array}$

a Temperature range of the vapor pressures used in the fit. 
TABLE 4. Enthalpies of vaporization and entroples of compression for 2,3-benzothlophene obtained from the Cox and Clapeyron equations a

\begin{tabular}{|c|c|c|c|c|c|c|}
\hline $\mathrm{T} / \mathrm{K}$ & $\Delta_{1}^{g} H_{m} / R K$ & $\Delta S_{c o m p, m} / R$ & $\mathrm{~T} / \mathrm{K}$ & & $\Delta_{1}^{g} H_{m} / R K$ & $\Delta S_{\text {comp,m }} / R$ \\
\hline $260.00 \mathrm{~b}$ & $6971 \pm 9$ & $-11.551 \pm 0.001$ & 520.00 & & $5118 \pm 27$ & $0.554 \pm 0.000$ \\
\hline $280.00^{b}$ & $6821 \pm 6$ & $-9.656 \pm 0.001$ & 540.00 & & $4960 \pm 35$ & $0.940 \pm 0.000$ \\
\hline $298.15 b$ & $6688 \pm 4$ & $-8.187 \pm 0.000$ & 560.00 & $b$ & $4794 \pm 43$ & $1.294 \pm 0.000$ \\
\hline $300.00 \mathrm{~b}$ & $6674 \pm 4$ & $-8.049 \pm 0.000$ & 580.00 & $b$ & $4619 \pm 53$ & $1.621 \pm 0.000$ \\
\hline 320.00 & $6530 \pm 3$ & $-6.673 \pm 0.000$ & 600.00 & $b$ & $4435 \pm 64$ & $1.924 \pm 0.000$ \\
\hline 340.00 & $6388 \pm 2$ & $-5.485 \pm 0.000$ & 620.00 & $b$ & $4238 \pm 75$ & $2.208 \pm 0.000$ \\
\hline 360.00 & $6249 \pm 1$ & $-4.451 \pm 0.000$ & 640.00 & $b$ & $4026 \pm 88$ & $2.473 \pm 0.000$ \\
\hline 380.00 & $6111 \pm 2$ & $-3.545 \pm 0.000$ & 660.00 & $b$ & $3794 \pm 103$ & $2.723 \pm 0.000$ \\
\hline 400.00 & $5975 \pm 3$ & $-2.747 \pm 0.000$ & 680.00 & $b$ & $3535 \pm 118$ & $2.960 \pm 0.000$ \\
\hline 420.00 & $5839 \pm 5$ & $-2.039 \pm 0.000$ & 700.00 & $b$ & $3241 \pm 136$ & $3.186 \pm 0.000$ \\
\hline 440.00 & $5701 \pm 8$ & $-1.407 \pm 0.000$ & 720.00 & $b$ & $2897 \pm 155$ & $3.401 \pm 0.000$ \\
\hline 460.00 & $5561 \pm 11$ & $-0.840 \pm 0.000$ & 740.00 & $b$ & $2471 \pm 178$ & $3.609 \pm 0.000$ \\
\hline 480.00 & $5418 \pm 15$ & $-0.330 \pm 0.000$ & 750.00 & $b$ & $2203 \pm 190$ & $3.710 \pm 0.000$ \\
\hline 500.00 & $5271 \pm 21$ & $0.133 \pm 0.000$ & & & & \\
\hline
\end{tabular}

a $\Delta S_{c o m p} / R=\ln \left(\mathrm{p} / \mathrm{p}^{\circ}\right)$ where $\mathrm{p}^{\circ}=101.325 \mathrm{kPa}$ and $\mathrm{R}=8.31451 \mathrm{~J} \cdot \mathrm{K} \cdot 1 \cdot \mathrm{mol}^{-1}$.

b Values at this temperature were calculated with extrapolated vapor pressures de'ermined from the fitted Cox coefficients. 
TABLE 5. Experimental molar enthalpy measurements for 2,3-benzothlophene $\left(R=8.31451 \mathrm{~J} \cdot \mathrm{K}^{-1} \cdot \mathrm{mol}^{-1}\right)$

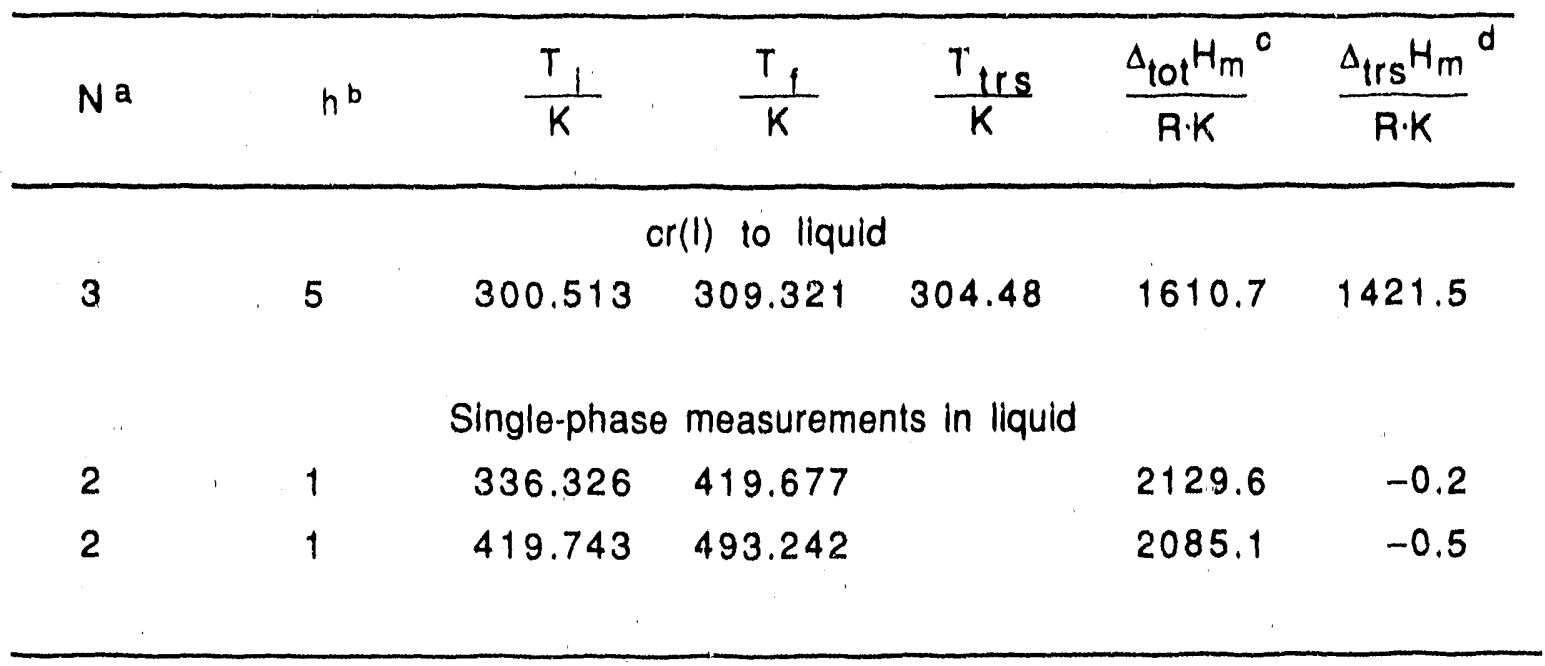

a Adiabatic series number

b Number of heating increments

c $\Delta_{\text {tot }} \mathrm{H}_{\mathrm{m}}$ is the molar energy input from the initial temperature $T_{1}$ to the final temperature $T_{f}$.

d $\Delta_{t r s} H_{m}$ is the net molar enthalpy of transition at the transition temperature $T_{\text {trs }}$ or the excess enthalpy relative the heat-capacity curve described in the text for singlephase measurements 
TABLE 6. Experimental molar heat capacities at vapor-saturation pressure determined by adlabatic calorimetry for 2,3-benzothiophene

$$
\left(R=8.31451 \mathrm{~J} \cdot \mathrm{K}^{-1} \cdot \mathrm{mol}^{-1}\right)
$$

$$
N^{a} \quad \frac{\langle T\rangle}{K} \quad \frac{\Delta T}{K} \quad \frac{C_{\text {sat m }}}{R} \quad N^{a} \quad \frac{\langle T\rangle}{K} \quad \frac{\Delta T}{K} \quad \frac{C_{\text {sat } m}{ }^{b}}{R}
$$

\begin{tabular}{llllllll} 
& & \multicolumn{9}{c}{$\operatorname{cr}(1)$} \\
3 & 277.639 & 8.0923 & 18.116 & 3 & 295.859 & 9.1962 & 20.703 \\
3 & 286.468 & 9.5153 & 18.853 & & & &
\end{tabular}

liquid

$\begin{array}{rrrrrrrr}3 & 314.236 & 9.8212 & 23.217 & 1 & 376.520 & 14.3005 & 25.511 \\ 1 & 316.171 & 9.4932 & 23.279 & 1 & 391.411 & 15.4508 & 26.043 \\ 2 & 319.796 & 10.9311 & 23.412 & 1 & 406.784 & 15.2627 & 26.597 \\ 1 & 326.953 & 12.0301 & 23.676 & 1 & 421.985 & 15.0804 & 27.150 \\ 2 & 330.697 & 10.8219 & 23.813 & 1 & 437.004 & 14.9085 & 27.688 \\ 1 & 339.570 & 13.1585 & 24.142 & 1 & 466.948 & 14.5798 & 28.754 \\ 1 & 353.320 & 14.2929 & 24.649 & 1 & 481.477 & 14.4339 & 29.254 \\ 1 & 365.030 & 8.2520 & 25.085 & 1 & 495.377 & 13.3466 & 29.729\end{array}$

a Adiabatic series number.

b Average heat capacity for a temperature increment of $\Delta T$ with a mean temperature $<T>$. 
TABLE 7. Experimental $C_{x, m}^{\prime \prime} / R$ values $\left(R=8.31451 \mathrm{~J} \cdot \mathrm{K} \cdot 1 \cdot \mathrm{mol}^{-1}\right)$

\begin{tabular}{|c|c|c|c|c|}
\hline & & \multirow{3}{*}{$\begin{array}{l}0.009735 \\
0.05576 \\
C_{x, m}^{\prime \prime} / R\end{array}$} & \multirow{3}{*}{$\begin{array}{l}0.018510 \\
0.05409 \\
C_{x, m}^{\prime \prime} / R\end{array}$} & \multirow{3}{*}{$\begin{array}{l}0.027797 \\
0.05576 \\
C_{x, m}^{\prime \prime} / R\end{array}$} \\
\hline & Vol. cell $/ \mathrm{cm}^{3}$ a & & & \\
\hline & $T / K$ & & & \\
\hline \multirow{23}{*}{ ' } & \multicolumn{4}{|c|}{ 2,3-Benzothiophene } \\
\hline & 315.0 & 22.57 & 23.21 & 23.15 \\
\hline & 335.0 & 23.74 & 24.06 & 23.75 \\
\hline & 355.0 & 24.49 & 24.83 & 24.59 \\
\hline & 375.0 & 25.18 & 25.46 & 25.33 \\
\hline & 395.0 & 26.25 & 26.19 & 26.08 \\
\hline & 415.0 & 26.94 & 27.07 & 26.96 \\
\hline & 435.0 & 27.67 & 28.01 & 27.68 \\
\hline & 455.0 & 29.48 & 28.80 & 28.43 \\
\hline & 475.0 & 30.55 & 29.45 & 29.27 \\
\hline & 495.0 & 31.81 & 30.52 & 30.04 \\
\hline & 515.0 & 33.12 & 31.13 & 30.73 \\
\hline & 535.0 & 34.10 & 32.08 & 31.51 \\
\hline & 555.0 & 35.09 & 32.77 & 32.16 \\
\hline & 575.0 & 35.88 & 33.54 & 33.06 \\
\hline & 595.0 & 36.87 & 34.66 & 33.79 \\
\hline & 615.0 & 39.14 & 35.94 & 34.33 \\
\hline & 635.0 & 40.56 & 36.46 & 35.08 \\
\hline & 655.0 & 42.02 & 37.17 & 35.63 \\
\hline & 675.0 & 43.90 & 37.83 & 36.63 \\
\hline & 695.0 & 46.18 & 39.35 & 38.09 \\
\hline & 715.0 & 48.53 & 40.43 & 39.23 \\
\hline & 735.0 & & 43.54 & 40.10 \\
\hline
\end{tabular}

a Volume measured at $298.15 \mathrm{~K}$ 
TABLE 8. Densitles and temperatures for the conversion from two phases to a single phase for 2,3-benzothlophene

\begin{tabular}{ll}
\hline$/(\mathrm{kg} \cdot \mathrm{m}-3)$ & $\mathrm{T} / \mathrm{K}$ \\
\hline 170.3 & 747.7 \\
230.5 & 756.6 \\
254.9 & 760.3 \\
333.3 & 763.2 \\
400.3 & 761.4 \\
423.6 & 761.4 \\
485.8 & 756.5 \\
557.5 & 744.4 \\
\hline
\end{tabular}


TABLE 9. Parameters for equations (11) and (12), critical constants and acentric factor for 2,3-benzothiophene

$\begin{array}{lrlr}A & 2.39637 & b_{0} & -0.33260 \\ B & -1.24937 & b_{1} & -0.68438 \\ C & 0.87029 & b_{2} & 1.08966 \\ & & b_{3} & -1.25335\end{array}$

$$
T_{c}=764 \mathrm{~K} \quad P_{c}=4.76 \mathrm{MPa} \quad \rho_{c}=354 \mathrm{~kg} \cdot \mathrm{m}^{-3} \quad \omega=0.306
$$


TABLE 10. Values of $C_{v, m}^{\prime \prime}\left(\rho=\rho_{\text {sat }}\right) / R$ and $C_{\text {sat, }} / R$ for $2,3-$ benzothiophene $\left(R=8.31451 \mathrm{~J} \cdot \mathrm{K}^{-1} \cdot \mathrm{mol}^{-1}\right)$

\begin{tabular}{cccccc}
\hline$T / K$ & $q_{V, m}^{\| l}\left(\rho=\rho_{s a t}\right) / R$ & $C_{s a t, m} / R$ & $T / K$ & $C_{v, m}^{\prime l}\left(p=\rho_{s a t}\right) / R$ & $C_{s a t, m} / R$ \\
\hline 300.0 & 22.6 & 22.6 & 540.0 & 31.3 & 31.3 \\
320.0 & 23.4 & 23.4 & 560.0 & 31.9 & 32.0 \\
340.0 & 24.2 & 24.2 & 580.0 & 32.6 & 32.7 \\
360.0 & 24.9 & 24.9 & 600.0 & 33.2 & 33.4 \\
380.0 & 25.6 & 25.6 & 620.0 & 33.8 & 34.0 \\
400.0 & 26.4 & 26.4 & 640.0 & 34.4 & 34.7 \\
420.0 & 27.1 & 27.1 & 660.0 & 34.9 & 35.5 \\
440.0 & 27.8 & 27.8 & 680.0 & 35.5 & 36.3 \\
460.0 & 28.5 & 28.5 & 700.0 & 36.2 & 37.4 \\
480.0 & 29.2 & 29.2 & 720.0 & 36.9 & 39.2 \\
500.0 & 29.9 & 29.9 & 740.0 & 38.1 & 42.7 \\
520.0 & 30.6 & 30.6 & 750.0 & 39.0 & 47.1 \\
\hline
\end{tabular}


TABLE 11. Molar thermodynamic functions at vapor-saturation pressure for 2,3-benzothiophene a $\left(R=8.31451 \mathrm{~J} \cdot \mathrm{K}^{-1} \cdot \mathrm{mol}^{-1}\right)$

\begin{tabular}{|c|c|c|c|c|c|c|c|}
\hline$\frac{T}{K}$ & $\frac{C_{\text {sat } m}}{R}$ & $\frac{\Delta_{0}^{\top} S_{m}}{R}$ & $\frac{\Delta_{0}^{T} H_{m}}{R T}$ & $\frac{T}{K}$ & $-\frac{C_{\text {sat m }}}{R}$ & $\frac{\Delta_{0}^{T} S_{m}}{R}$ & $\frac{\Delta_{0}^{T} H_{m}}{R T}$ \\
\hline \multicolumn{8}{|c|}{ liquid } \\
\hline $260.00 \mathrm{~b}$ & 21.280 & 23.343 & 15.121 & 500.00 & 29.905 & 39.782 & 20.156 \\
\hline $280.00 \mathrm{~b}$ & 21.984 & 24.946 & 15.586 & 520.0 & 30.61 & 40.97 & 20.54 \\
\hline $298.15^{b}$ & 22.632 & 26.346 & 15.995 & 540.0 & 31.31 & 42.14 & 20.93 \\
\hline $300.00 \mathrm{~b}$ & 22.699 & 26.487 & 16.037 & 560.0 & 32.00 & 43.29 & 21.31 \\
\hline $304.48 \mathrm{~b}$ & 22.861 & 26.824 & 16.136 & 580.0 & 32.68 & 44.42 & 21.69 \\
\hline 320.00 & 23.419 & 27.975 & 16.475 & 600.0 & 33.36 & 45.54 & 22.07 \\
\hline 340.00 & 24.157 & 29.416 & 16.906 & 620.0 & 34.03 & 46.65 & 22.45 \\
\hline 360.00 & 24.898 & 30.818 & 17.329 & 640.0 & 34.73 & 47.74 & 22.82 \\
\hline 380.00 & 25.636 & 32.184 & 17.747 & 660.0 & 35.48 & 48.82 & 23.19 \\
\hline 400.00 & 26.352 & 33.517 & 18.159 & 680.0 & 36.34 & 49.89 & 23.56 \\
\hline 420.00 & 27.078 & 34.821 & 18.567 & 700.0 & 37.44 & 50.96 & 23.94 \\
\hline 440.00 & 27.796 & 36.097 & 18.970 & 720.0 & 39.16 & 52.03 & 24.34 \\
\hline 460.00 & 28.509 & 37.348 & 19.369 & 740.0 & 42.70 & 53.15 & 24.78 \\
\hline 480.00 & 29.201 & 33.576 & 19.764 & 750.0 & 47.12 & 53.75 & 25.05 \\
\hline
\end{tabular}

a Values listed in this table are reported with one digit more than is justified by the experimental uncertainty. This is to avoid round-off errors in the calculation of values listed in table 12.

b Values at this temperature were calculated with graphically extrapolated heat capacities. 
TABLE 13. Comparison of experimental and estimated critical properties for 2,3-benzothiophene

\begin{tabular}{ccccc} 
& This research & Lydersen(53) & Joback(55) & Somayajulu(54) \\
$T_{\mathrm{c}} / \mathrm{K}$ & $764 \pm 2$ & 756 & 755 & $767 \mathrm{a}$ \\
$\mathrm{\rho}_{\mathrm{c}} / \mathrm{kg} \cdot \mathrm{m}^{-3}$ & $354 \pm 7$ & 354 & 366 & 368 \\
$\mathrm{P}_{\mathrm{c}} / \mathrm{MPa}$ & $4.76 \pm 0.10 \mathrm{~b}$ & 4.14 & 4.58 & 4.63 \\
\hline
\end{tabular}

a This value was calculated with equation (12) of reference 54.

b This value was derived using the fitting procedure described in the text. $T_{C}$ and $\rho_{c}$ were obtained graphically with figure 1. 

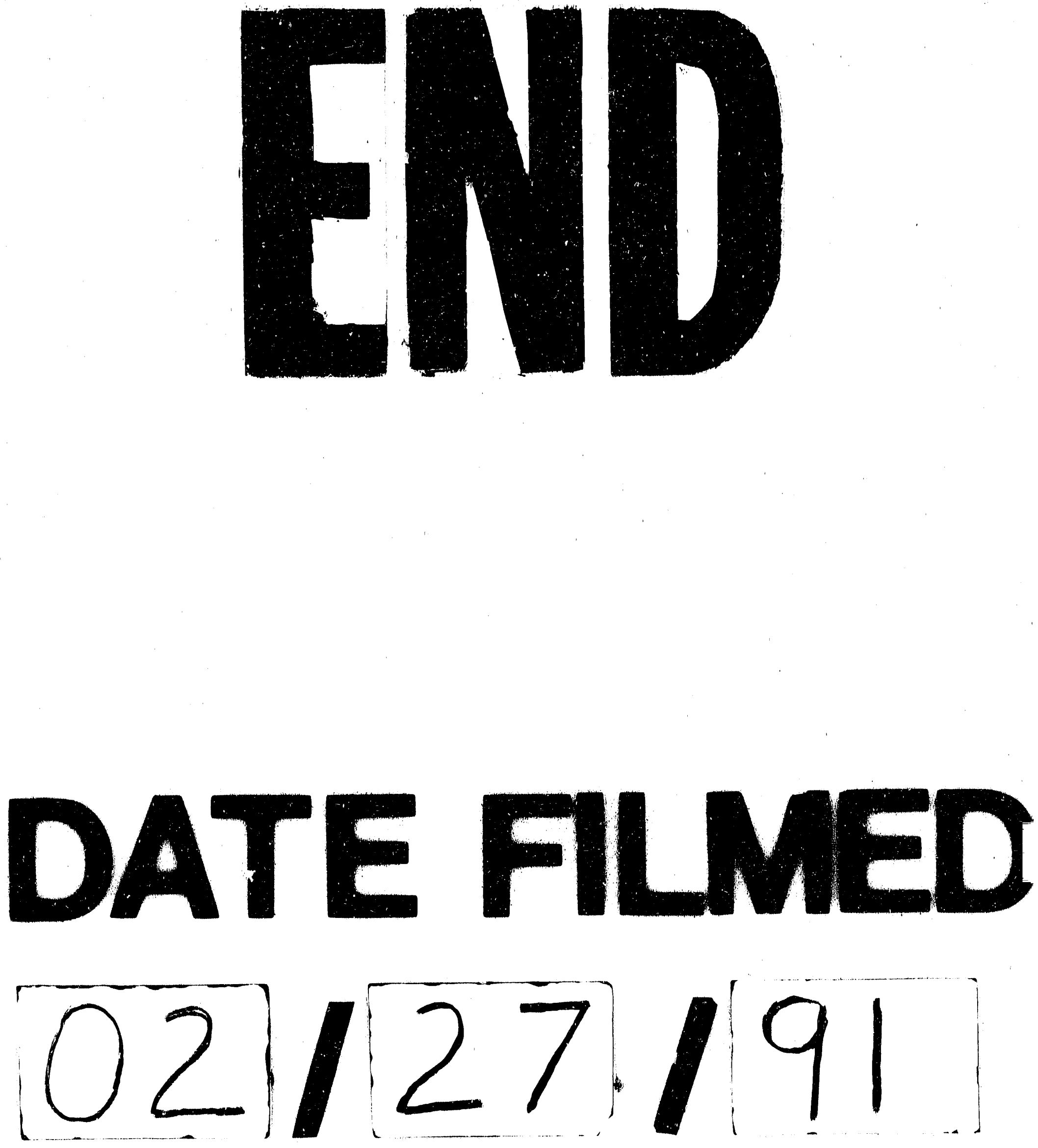
